Check for updates

Cite this: RSC Adv., 2018, 8, 8372

Received 31st December 2017

Accepted 16th February 2018

DOI: 10.1039/c7ra13776a

rsc.li/rsc-advances

\section{Investigation on converting 1-butene and ethylene into propene via metathesis reaction over W-based catalysts $\uparrow$}

\author{
Guangzheng Zuo, Yuebing Xu, Jiao Zheng, Feng Jiang and Xiaohao Liu (D) *
}

\begin{abstract}
Supported W catalysts were extensively investigated for the conversion of 1-butene and ethylene into propene by metathesis reaction. The performance of catalysts was compared by using unsupported $\mathrm{WO}_{3}$, pure SBA-15, supported W/SBA-15 with different $\mathrm{W}$ loadings, varied calcination temperatures, and by changing the pretreatment gas atmosphere. The above catalytic results could be employed to deduce the reaction mechanism combined with characterization techniques such as BET, XRD, UV-vis DRS, Raman, pyridine-IR, XPS, and $\mathrm{H}_{2}$-TPR. In this study, over the investigated W/SBA-15 catalysts, the results showed that the silanol group $(\mathrm{Si}-\mathrm{OH})$ in SBA-15 could act as a weak Brønsted acid site for 1-butene isomerization. However, the metathesis reaction was catalyzed by $\mathrm{W}$-carbene species. The initially formed $\mathrm{W}$-carbenes $\left(\mathrm{W}=\mathrm{CH}-\mathrm{CH}_{3}\right)$ as active sites were derived from the partially reduced isolated tetrahedral $\mathrm{WO}_{x}$ species which contained $\mathrm{W}=\mathrm{O}$ or $\mathrm{W}-\mathrm{OH}$ bonds in $\mathrm{W}^{5+}$ species as corresponding Lewis or Brønsted acid sites. Furthermore, the W/SBA-15 being pretreated by $\mathrm{H}_{2} \mathrm{O}$ led to a complete loss of the metathesis activity. This was mainly due to the sintering of isolated $\mathrm{WO}_{x}$ species to form an inactive crystalline $\mathrm{WO}_{3}$ phase as demonstrated by XRD patterns. On the other hand, the reduction of $\mathrm{WO}_{x}$ species remarkably suppressed by $\mathrm{H}_{2} \mathrm{O}$ pretreatment was also responsible for the metathesis deactivation. This study provides molecular level mechanisms for the several steps involved in the propene production, including 1-butene isomerization, $\mathrm{W}$-carbene formation, and metathesis reaction.
\end{abstract}

\section{Introduction}

Propene is one of the fastest growing raw materials as a key building block in the chemical industry, driven primarily by the high growth rate of polypropene consumption. ${ }^{1,2}$ Also, propene is used in the production of propene oxide which is a chemical precursor for the synthesis of propene glycol and polyols. ${ }^{3}$ The rest of propene is consumed for the synthesis of acrylonitrile, oxo-alcohol, cumene, and many other industrially relevant chemicals. ${ }^{4}$ The market for propene has been continuously growing at average rates of $4-5 \%$ per year. More than 50 million tons of additional capacity will be needed by the year of 2020 . Currently, approximately $42 \%$ of propene is primarily derived from steam cracking of naphtha and about $39 \%$ of it is recovered from fluid catalytic cracking (FCC)..$^{5-8}$ In recent years, dehydrogenation of propane (PDH), ${ }^{9}$ methanol-to-olefins (MTO),${ }^{10}$ and Fischer-Tropsch to olefins (FTO) ${ }^{11}$ processes for the production of propene have been blooming in view of the availability of cheap propane in shale gas and the availability of coal-, natural gas-, and biomass-derived syngas. Especially, FTO

Department of Chemical Engineering, School of Chemical and Material Engineering, Jiangnan University, Wuxi 214122, China. E-mail: liuxh@jiangnan.edu.cn

$\dagger$ Electronic supplementary information (ESI) available. See DOI: $10.1039 / \mathrm{c} 7 \mathrm{ra} 13776 \mathrm{a}$ route can provide a reliable solution for meeting the demand for propene by utilizing the abovementioned alternative carboncontaining resources via syngas conversion. ${ }^{12}$

Compared with the highly selective production of propene via PDH route, the FTO route generally produces the mixed light $\alpha$-olefins such as ethylene, propene, and 1-butene. ${ }^{13,14}$ In spite of the high selectivity to total light $\alpha$-olefins, the selectivity to propene is usually lower than $40 \%$. Therefore, it is necessary for us to search for an efficient approach to significantly enhance the propene fraction in light $\alpha$-olefins in order to meet its growing demand. Olefin metathesis is a highly versatile process for interconverting olefinic hydrocarbons. It is an efficient approach for us to remarkably enhance the selectivity to propene by using the metathesis reaction of 1-butene and ethylene from FTO route.

Various supported transition metal oxides have been used as heterogeneous catalysts for metathesis reaction, including tungsten (W), ${ }^{15-17}$ molybdenum (Mo), ${ }^{18,19}$ and rhenium (Re). ${ }^{20,21}$ Among these catalysts, supported $\mathrm{W}$ catalysts obtain the largest number of commercial applications because of its benefits such as relatively lower price, better stability, and better resistance to poisoning. ${ }^{22}$ Despite that numerous literatures have reported the olefin metathesis by the supported $\mathrm{W}$ catalysts, most of them focus on conversion of 2-butene and ethylene into propene, ${ }^{23-25}$ and its reverse process. ${ }^{26,27}$ Self-metathesis of 1- 
butene $^{28-30}$ or 2-butene, ${ }^{31}$ 2-pentene metathesis, ${ }^{32}$ and metathesis of 1-butene and ethylene $\mathrm{e}^{33-35}$ have also been paid attention to. However, for converting FTO-based $\alpha$-olefin products such 1 butene and ethylene into propene by metathesis reaction, the detailed investigation on the reaction mechanism is still insufficient over past studies. Therefore, the molecular level insights into the nature of surface active tungsten oxide $\left(\mathrm{WO}_{x}\right)$ sites, catalyst activation, and reaction mechanism still need to be taken in order to guide the rational design of advanced catalysts.

It is generally accepted that the high dispersion of $\mathrm{WO}_{x}$ and its existing state on support surface play crucial roles in the catalyst efficiency. Especially, the isolated $\mathrm{WO}_{x}$ species might be responsible for metathesis activity. ${ }^{36}$ And these factors depend on the properties of supports and the preparation methods. Therefore, we have designed a series of supported $\mathrm{W}$ catalysts with different physicochemical properties and varied preparation conditions to regulate the $\mathrm{WO}_{x}$ species state. In this study, several supports such as $\mathrm{SiO}_{2}, \gamma-\mathrm{Al}_{2} \mathrm{O}_{3}, \mathrm{TiO}_{2}$, and SBA-15 are selected for the preparation of $\mathrm{W}$ catalysts, and unsupported $\mathrm{WO}_{3}$ catalyst is also prepared as a reference. The as-prepared $\mathrm{W}$ catalysts and pure support are used for the metathesis reaction of 1-butene and ethylene; this can provide important information for speculation on what species in catalysts contribute to the 1-butene isomerization and the olefin metathesis for the formation of propene. Furthermore, the calcination temperature and $\mathrm{W}$ loading in catalyst may affect the aggregation of $\mathrm{WO}_{x}$ species to lead to the changing ratio of isolated $\mathrm{WO}_{x}$ species to crystalline $\mathrm{WO}_{3}$, which can confirm the importance of the high dispersion of $\mathrm{WO}_{x}$ phase.

In addition, prior to metathesis reaction, the different pretreatment gas, such as the oxidizing gas $\left(\mathrm{O}_{2}\right.$ and $\left.\mathrm{H}_{2} \mathrm{O}\right)$, reducing gas $\left(\mathrm{H}_{2}\right)$, and inert gas $\left(\mathrm{N}_{2}\right)$, can regulate the initially existing state of $\mathrm{WO}_{x}$ species. The induction period for the formation of propene over gas-pretreated supported $\mathrm{W}$ catalysts could be helpful for us to discern that either oxidative or reductive state of $\mathrm{WO}_{x}$ species is responsible for metathesis reaction. It should be noted that $\mathrm{H}_{2} \mathrm{O}$ is used to pretreat the supported $\mathrm{W}$ catalysts before reaction, which is based on the following considerations. On the one hand, the pretreatment with $\mathrm{H}_{2} \mathrm{O}$ might result in the oxidation of $\mathrm{WO}_{x}$ species; on the other hand, the pretreatment with $\mathrm{H}_{2} \mathrm{O}$ might lead to more crystalline $\mathrm{WO}_{3}$ phase due to the sintering. The designed pretreatment methods might make obvious transformation between oxidative and reductive $\mathrm{WO}_{x}$ species, or between isolated and crystalline $\mathrm{WO}_{x}$ phases. The metathesis activity over $\mathrm{H}_{2} \mathrm{O}$-pretreated $\mathrm{W}$ catalysts could provide further verification on the proposed mechanism as reflected by abovementioned a series of investigations. In order to accurately correlate the relationship between the structure of supported $\mathrm{W}$ catalysts and catalytic performance, various characterization methods such as BET, XRD, UV-vis DRS, Raman, pyridine-IR, XPS, and $\mathrm{H}_{2}$-TPR have been applied to measuring the physicochemical properties of catalysts. Finally, the influences of WHSV and reaction temperature on metathesis reaction are also investigated to obtain the optimal catalytic activity and propene selectivity. And the mechanisms for 1-butene isomerization, W-carbene formation, and metathesis reaction on SBA-15 supported W catalysts have been proposed and discussed in detail.

\section{Experimental}

\subsection{Catalyst preparation}

The supported tungsten catalysts were prepared by an incipient wetness impregnation (IWI) method as described in literature. ${ }^{37}$ The SBA-15 support was purchased from Jiaxing Tanli New Materials Development Co., Ltd (China). Ammonium metatungstate (AMT, $\left(\mathrm{NH}_{4}\right)_{6} \mathrm{H}_{2} \mathrm{~W}_{12} \mathrm{O}_{40} \cdot x \mathrm{H}_{2} \mathrm{O}, 99.5 \%$, Aladdin) was used as tungsten precursor. Briefly, prior to impregnation, SBA15 was dried in an oven at $120^{\circ} \mathrm{C}$ for $2 \mathrm{~h}$. Then, as-calculated amount of AMT aqueous solution was added into the dried SBA-15. After impregnation, the sample was dried at $120{ }^{\circ} \mathrm{C}$ overnight and followed by calcination in air at $550{ }^{\circ} \mathrm{C}$ for $4 \mathrm{~h}$ with a heating rate of $1{ }^{\circ} \mathrm{C} \mathrm{min}^{-1}$. The obtained catalysts were labelled as $x \mathrm{~W} / \mathrm{SBA}-15$ where $x$ represents $\mathrm{WO}_{3}$ content in weight percentage. The supported $\mathrm{W}$ catalysts with different supports such as $\mathrm{SiO}_{2}, \gamma-\mathrm{Al}_{2} \mathrm{O}_{3}$, and anatase- $\mathrm{TiO}_{2}$ were prepared by the same method. In addition, the unsupported $\mathrm{WO}_{3}$ used as a reference was prepared by calcination of AMT with same procedures for supported catalysts.

\subsection{Catalyst characterization}

Brunauer-Emmett-Teller (BET) surface area, pore volume, pore size, and the adsorption-desorption isotherms were measured by using a Micromeritics ASAP 2020. The X-ray diffraction (XRD) patterns of samples were recorded on a Bruker AXS D8 Advance $\mathrm{X}$-ray diffractometer using $\mathrm{Cu}(\mathrm{K} \alpha)$ radiation with $0.02^{\circ}$ step in the $2 \theta$ range from 10 to $80^{\circ}$. Diffuse-reflectance UV-vis spectra (UV-vis DRS) were obtained in the range of 200-700 nm with a Shimadzu UV-3600 Plus Spectrometer, using $\mathrm{BaSO}_{4}$ as reference. The Raman spectra of the samples were recorded on a Renishaw Micro Raman Spectrometer in the range from 200 to $1200 \mathrm{~cm}^{-1}$ (excitation line: $785 \mathrm{~nm}$ of diode solid-state laser). The XPS data were collected using X-ray photoelectron spectrometer Thermo SCIENTIFIC ESCALAB 250xi with an Al-K $\alpha$ $(1486.8 \mathrm{eV}) \mathrm{X}$-ray source. The pyridine-absorption infrared spectra (pyridine-IR) were recorded on a Thermo Nicolet 5700 FT-IR Spectrometer. Temperature programmed reduction of hydrogen $\left(\mathrm{H}_{2}\right.$-TPR) were recorded on a Xianquan TP5076 automated chemisorption analyzer equipped with a TCD detector.

\subsection{Catalytic evaluation}

The catalytic experiments of $\mathrm{W}$-based catalysts for metathesis of ethylene and 1-butene to propene were carried out in a fixed bed reactor. $0.5 \mathrm{~g}$ of shaped catalyst (40-60 mesh) was placed at the center of reactor. The $\mathrm{W}$-based catalysts need to be pretreated at $550{ }^{\circ} \mathrm{C}$ and 1 bar for $4 \mathrm{~h}$ by pure $\mathrm{N}_{2}$ or other gases such as pure $\mathrm{H}_{2}, 1 \% \mathrm{O}_{2} / \mathrm{N}_{2}$, and water vapor in $\mathrm{N}_{2}$. It should be noted that the flow rate of pretreated gas was $35 \mathrm{~mL} \mathrm{~min}^{-1}$. Water vapor generated in a flask at $80{ }^{\circ} \mathrm{C}$ was introduced into reactor with a flowing $\mathrm{N}_{2} \cdot{ }^{38}$ In the case of water pretreatment, the catalyst was further flushed with inert $\mathrm{N}_{2}$ at high temperature of $450{ }^{\circ} \mathrm{C}$ for $3 \mathrm{~h}$ in order to avoid the influence of the remaining presence 
of $\mathrm{H}_{2} \mathrm{O}$ prior to the reaction. After treatment and cooling to designed reaction temperature, for example $450{ }^{\circ} \mathrm{C}$, the mixed feed gas (molar ratio ethylene/1-butene $=2 / 1$ ) was fed into the catalyst bed. The gas weight hourly space velocity (WHSV), defined as the weight ratio of mixed gas to catalyst packed, was regulated at $1.8 \mathrm{~h}^{-1}$. The flow rates of ethylene and 1-butene were controlled by two mass flow controllers (MFC, Brooks, model $5800 \mathrm{E})$. All the products were analyzed online by a gas chromatograph (7820A, Agilent) with a $\mathrm{HP}-$ plot $/ \mathrm{Al}_{2} \mathrm{O}_{3} \mathrm{KCl}$ column using a flame ionization detector (FID). The 1-butene conversion and products selectivity were calculated as the reaction reached steady state according to the following equations:

Conversion of 1-butene (\%)

$$
=\frac{\left(\mathrm{C}_{3}^{=}\right)_{n}+2\left(\mathrm{i}-\mathrm{C}_{4}^{=}\right)_{n}+2\left(2-\mathrm{C}_{4}^{=}\right)_{n}+4\left(\mathrm{C}_{5+}\right)_{n}}{\left(\mathrm{C}_{3}^{=}\right)_{n}+2\left(1-\mathrm{C}_{4}^{=}\right)_{n}+2\left(\mathrm{i}-\mathrm{C}_{4}^{=}\right)_{n}+2\left(2-\mathrm{C}_{4}^{=}\right)_{n}+4\left(\mathrm{C}_{5+}\right)_{n}}
$$

Selectivity to propene $(\%)$

$$
=\frac{\left(\mathrm{C}_{3}^{=}\right)_{m}}{\left(\mathrm{C}_{3}^{=}\right)_{m}+\left(\mathrm{i}-\mathrm{C}_{4}^{=}\right)_{m}+\left(2-\mathrm{C}_{4}^{=}\right)_{m}+\left(\mathrm{C}_{5+}\right)_{m}}
$$

where $\left(\mathrm{C}_{3}^{=}\right)_{n}$ is the molar number of propene, $\left(\mathrm{C}_{3}^{=}\right)_{m}$ is the weight percentage of propene in all hydrocarbon products. In addition, the specific activity is also calculated as the converted amount of 1-butene in molar base per gram of catalyst per hour.

\section{Results and discussion}

\subsection{Effect of support character}

Table $\mathrm{S} 1 \dagger$ summarizes the BET specific surface area, pore volume, pore size, W surface density, and acidity of as-prepared supports and W-contained catalysts. It is clear that SBA-15 exhibits the highest specific surface area and pore volume of $719 \mathrm{~m}^{2} \mathrm{~g}^{-1}$ and $1.09 \mathrm{~cm}^{3} \mathrm{~g}^{-1}$, respectively. In contrast, the corresponding values for $\mathrm{TiO}_{2}$ are the lowest at $13 \mathrm{~m}^{2} \mathrm{~g}^{-1}$ and $0.06 \mathrm{~cm}^{3} \mathrm{~g}^{-1}$. The structural properties of selected support directly determine the tungsten oxide surface density $\left(\mathrm{W} \mathrm{nm}^{-2}\right)$. As listed in Table $\mathrm{S} 1, \uparrow$ the surface $\mathrm{W}$ density is linearly increased with a decrease in the surface area, which is calculated by using the initial BET surface area of the oxide support. ${ }^{39}$ For acidity, the $8 \mathrm{~W} / \mathrm{SBA}-15$ and $8 \mathrm{~W} / \mathrm{SiO}_{2}$ display the low content in Brønsted acid which is not observed for $8 \mathrm{~W} / \gamma-\mathrm{Al}_{2} \mathrm{O}_{3}$ and $8 \mathrm{~W} / \mathrm{TiO}_{2}$. In spite of absence of Brønsted acid, $8 \mathrm{~W} / \gamma-\mathrm{Al}_{2} \mathrm{O}_{3}$ shows the significantly highest content in Lewis acid. The absence of Brønsted acid over $8 \mathrm{~W} / \gamma-\mathrm{Al}_{2} \mathrm{O}_{3}$ catalyst is similar to the result reported by $\mathrm{Xu}$ et $a .^{17}$ In general, the content in Lewis acid is always much higher than that for Brønsted acid over as-prepared Wcontained catalysts.

The XRD patterns of supported $\mathrm{W}$ catalysts are shown in Fig. S1. $\dagger$ In the case of $8 \mathrm{~W} / \mathrm{SiO}_{2}$, the diffraction peaks assigned to monoclinic crystalline $\mathrm{WO}_{3}$ (PDF\#72-1465) appear clearly, which are located at 23.1, 23.6, 24.3, 28.9, 33.3, and $34.1^{\circ}$. Those diffraction peaks could be observed but much weaker over $8 \mathrm{~W} /$ $\mathrm{TiO}_{2}$ catalyst (Fig. S1a and $\mathrm{b} \dagger$ ). However, both 8W/SBA-15 and $8 \mathrm{~W} / \gamma-\mathrm{Al}_{2} \mathrm{O}_{3}$ catalysts do not show any diffraction peak for abovementioned $\mathrm{WO}_{3}$, which might be ascribed to the $\mathrm{W}$ highly dispersed on SBA-15 and its strong interaction with $\gamma-\mathrm{Al}_{2} \mathrm{O}_{3}$, respectively. ${ }^{40}$ The $\mathrm{W}$ loaded on $\mathrm{TiO}_{2}$ with small surface area leads to a smaller amount of the crystalline $\mathrm{WO}_{3}$ formed compared to that for $\mathrm{SiO}_{2}$ support, which might result from more favorable wetting of $\mathrm{TiO}_{2}$ by $\mathrm{WO}_{3}$ than that on $\mathrm{SiO}_{2}$. For comparison, the prepared unsupported $\mathrm{WO}_{3}$ reference exhibits the intensive diffraction peaks indicating the presence of $\mathrm{WO}_{3}$ (Fig. S1c $\dagger$ ).

The UV-vis DRS spectra for various W-contained compounds and supported $\mathrm{W}$ catalysts are presented in Fig. 1. Comparison of the $\mathrm{Na}_{2} \mathrm{WO}_{4}, \mathrm{AMT}$, and unsupported $\mathrm{WO}_{3}$ compounds with the supported $\mathrm{W}$ catalysts could provide reliable information about the local molecular coordination and bonding of supported tungsten oxide catalysts (Fig. 1a). In detail, $\mathrm{Na}_{2} \mathrm{WO}_{4}$ possesses a single ligand-to-metal charge transfer (LMCT) band maxima occurring at $\sim 208 \mathrm{~nm}$; this represents the isolated tetrahedral structure of $\mathrm{WO}_{x}$. Ammonium metatungstate (AMT) precursor indicates characteristic spectrum with two maxima at 250 and $330 \mathrm{~nm}$; this is related to the LMCT assigned to the
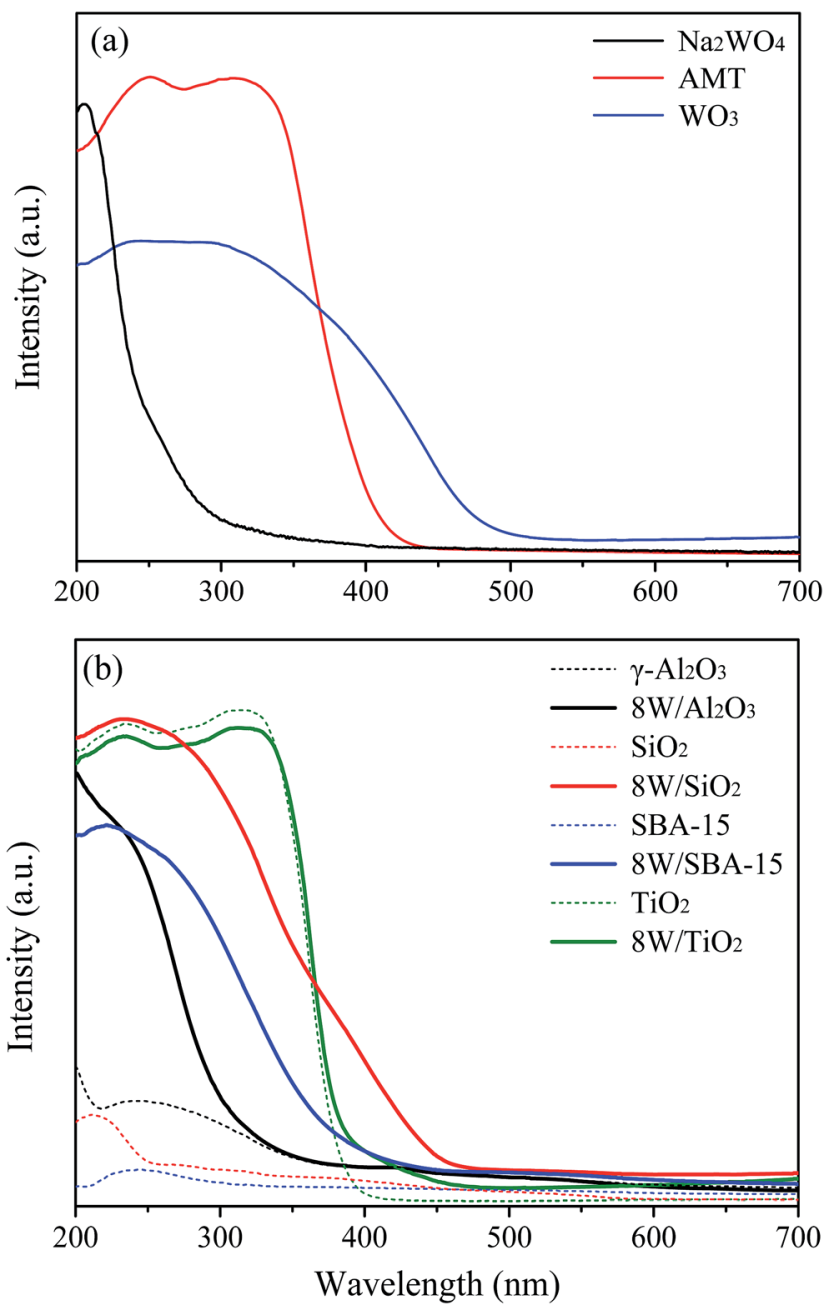

Fig. 1 UV-vis DRS spectra of (a) various W-containing compounds, and (b) $8 \mathrm{wt} \% \mathrm{~W}$-containing catalysts and their corresponding support materials. 
oligomeric octahedral structure of $\mathrm{WO}_{x}$ species. For as-prepared unsupported $\mathrm{WO}_{3}$, it exhibits a broad band at $\sim 400 \mathrm{~nm}$ attributed to $\mathrm{d}-\mathrm{d}$ band of crystalline $\mathrm{WO}_{3} \cdot{ }^{41}$ As exhibited in Fig. $1 \mathrm{~b}, 8 \mathrm{~W} / \gamma-\mathrm{Al}_{2} \mathrm{O}_{3}$ gives rise to single band at $\sim 220 \mathrm{~nm}$ indicating the presence of isolated tetrahedral $\mathrm{WO}_{x}{ }^{42}$ For $\mathrm{W}$ supported on $\mathrm{TiO}_{2}$, UV-vis spectra have no clear difference with that for $\mathrm{TiO}_{2}$ support except for a weak band at $\sim 400 \mathrm{~nm}$ which suggests that a small amount of crystalline $\mathrm{WO}_{3}$ is present. ${ }^{43} \mathrm{To}$ be significantly different from above two catalysts, both $8 \mathrm{~W} /$ $\mathrm{SiO}_{2}$ and $8 \mathrm{~W} / \mathrm{SBA}-15$ display a typical band at $\sim 225 \mathrm{~nm}$ with a weaker band at $\sim 270 \mathrm{~nm}$ indicating the presence of the isolated tetrahedral structure and the oligomeric octahedral structure of $\mathrm{WO}_{x}$ species, respectively. ${ }^{44}$ However, compared to the $8 \mathrm{~W} / \mathrm{SBA}-15,8 \mathrm{~W} / \mathrm{SiO}_{2}$ exhibits one more band at $\sim 400 \mathrm{~nm}$ for crystalline $\mathrm{WO}_{3}$, which is well in agreement with the XRD results.

Fig. $\mathrm{S} 2 \uparrow$ illustrates the Raman spectra of various supports and corresponding W-loaded catalysts compared at a similar net intensity. It can be seen that $8 \mathrm{~W} / \mathrm{TiO}_{2}$ exhibits a weak new band for crystalline $\mathrm{WO}_{3}$ phase at $\sim 805 \mathrm{~cm}^{-1}$ relative to that for $\mathrm{TiO}_{2}$ support. When $\mathrm{W}$ is loaded into $\gamma-\mathrm{Al}_{2} \mathrm{O}_{3}$, a single band at $\sim 975 \mathrm{~cm}^{-1}$ is assigned to the terminal $\nu_{\mathrm{s}}(\mathrm{W}=\mathrm{O})$ of surface $\mathrm{WO}_{x}{ }^{45}$ The Raman spectrum of $8 \mathrm{~W} / \mathrm{SiO}_{2}$ includes notable bands at $274,715,805$, and $980 \mathrm{~cm}^{-1}$; these bands feature the deformation vibration mode of $\mathrm{W}-\mathrm{O}-\mathrm{W}$, bending vibration mode of $\mathrm{W}-\mathrm{O}$, symmetric stretching vibration $\left(\nu_{\mathrm{s}}\right)$ mode of $\mathrm{W}-\mathrm{O}$, and symmetric stretching vibration mode of terminal $\mathrm{W}=\mathrm{O}$ of surface $\mathrm{WO}_{x}$, respectively. ${ }^{42} 8 \mathrm{~W} / \mathrm{SBA}-15$ exhibits significantly weaker bands at 274,715 , and $805 \mathrm{~cm}^{-1}$ compared to that for $8 \mathrm{~W} / \mathrm{SiO}_{2}$, and similar intensity of band at $980 \mathrm{~cm}^{-1}$. To this end, we elucidated the structural differences of $\mathrm{WO}_{x}$ over supported $\mathrm{W}$ catalysts through the XRD patterns, UV-vis spectra, and Raman spectra analysis.

The catalytic results of as-prepared $\mathrm{W}$ catalysts supported on different supports for metathesis of ethylene and 1-butene are shown in Fig. 2. The unsupported $\mathrm{WO}_{3}$ catalyst displays the lowest 1-butene conversion and nearly no detectable selectivity to propene. In spite of substantially higher 1-butene conversion with a gradual deactivation over supported $8 \mathrm{~W} / \mathrm{TiO}_{2}$, there is almost no propene formed via metathesis reaction. The 1butene is dominantly transformed into trans-2-butene and cis-2butene via double bond isomerization over both $\mathrm{WO}_{3}$ and $8 \mathrm{~W} /$ $\mathrm{TiO}_{2}$ (Fig. $2 \mathrm{c}$ and Table S2 $\dagger$ ). According to the above results, it can be deduced that the crystalline $\mathrm{WO}_{3}$ did not provide active sites for the metathesis reaction to convert isomerized 2-butene and ethylene into propene. Over $8 \mathrm{~W} / \mathrm{TiO}_{2}$ catalyst, the catalytic results suggest that the metathesis reaction might be closely related to the terminal $\mathrm{W}=\mathrm{O}$ of surface $\mathrm{WO}_{x}$, since the Raman band of it in isolated tetrahedral $\mathrm{WO}_{x}$ at $\sim 980 \mathrm{~cm}^{-1}$ is not present for $8 \mathrm{~W} / \mathrm{TiO}_{2}$ but clear for $8 \mathrm{~W} / \mathrm{SiO}_{2}, 8 \mathrm{~W} / \mathrm{SBA}-15$, and $8 \mathrm{~W} /$ $\gamma-\mathrm{Al}_{2} \mathrm{O}_{3}$ (Fig. S2b $\dagger$ ), and the latter three catalysts show much higher selectivity to propene except for $8 \mathrm{~W} / \gamma-\mathrm{Al}_{2} \mathrm{O}_{3} .8 \mathrm{~W} / \gamma-\mathrm{Al}_{2} \mathrm{O}_{3}$ exhibits relatively lower metathesis activity compared to that for $8 \mathrm{~W} / \mathrm{SiO}_{2}$ and $8 \mathrm{~W} / \mathrm{SBA}-15$, which possibly results from their significant difference in acidity. It can be seen that $8 \mathrm{~W} / \gamma-\mathrm{Al}_{2} \mathrm{O}_{3}$ contains appreciable number of Lewis acid sites with no detectable Brønsted acid sites (Table S1 $\dagger$ ), which favors the
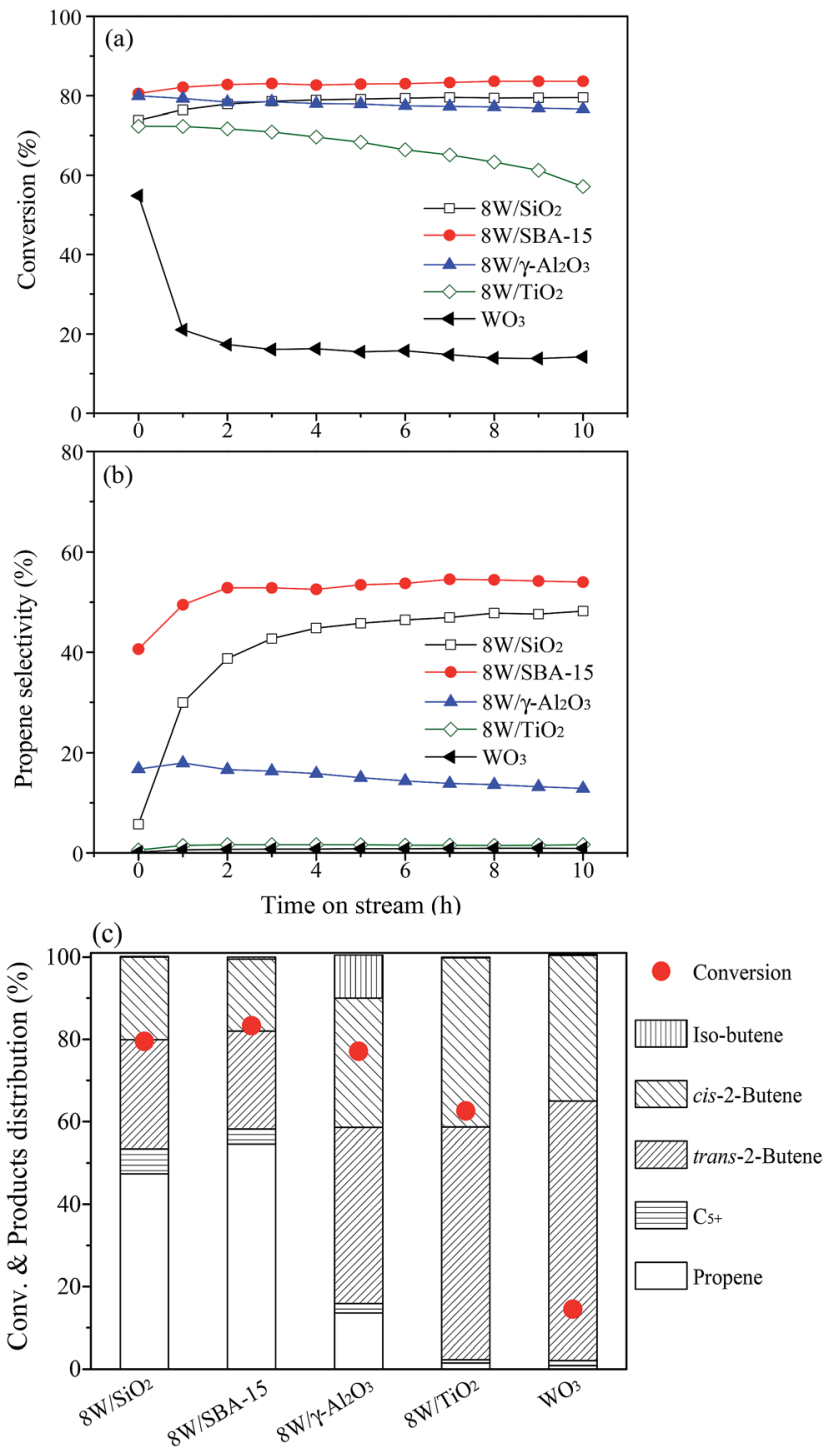

Fig. 2 Time-dependence of 1-butene conversion (a), propene selectivity (b), and products distribution (c) obtained over $\mathrm{WO}_{3}$ and various $8 \mathrm{wt} \% \mathrm{~W}$-containing catalysts at the reaction conditions of $450{ }^{\circ} \mathrm{C}, 0.1 \mathrm{MPa}, 0.5 \mathrm{~g}$ of catalyst weight, $1.8 \mathrm{~h}^{-1}$ of WHSV, and an ethylene/1-butene molar ratio of 2 .

isomerization of 1-butene to iso-butene via skeletal isomerization. The metathesis reaction is difficult to occur over isobutene and ethylene. ${ }^{46}$ Besides, the presence of Brønsted acid sites might be favorable for promoting the metathesis reaction of 2-butene and ethylene for the formation of desired propene. Indeed, the higher selectivity to propene has been obtained over $8 \mathrm{~W} / \mathrm{SiO}_{2}$ and $8 \mathrm{~W} / \mathrm{SBA}-15$ with the presence of suitable amount of Brønsted acid sites (Fig. 2c and Table S2 $\dagger$ ). As shown in Fig. 2, $8 \mathrm{~W} / \mathrm{SBA}-15$ indicates the highest 1-butene conversion and selectivity to propene, which can be explained from two aspects. On the one hand, more Lewis and Brønsted acid sites are available for $8 \mathrm{~W} / \mathrm{SBA}-15$ compared to that for $8 \mathrm{~W} / \mathrm{SiO}_{2}$; on the other hand, the W highly dispersed on SBA-15 with large surface area leads to more formation of the terminal $\mathrm{W}=\mathrm{O}$ in isolated tetrahedral structure of surface $\mathrm{WO}_{x}$ (Fig. 1 and $\mathrm{S} 2 \mathrm{~b} \uparrow$ ) due to 
more silanol group ( $\mathrm{Si}-\mathrm{OH})$ interacted with the supported surface $\mathrm{WO}_{x}$ species. ${ }^{30}$ Based on the abovementioned catalytic results and discussions, the metathesis reaction strongly depends on the terminal $\mathrm{W}=\mathrm{O}$ of isolated tetrahedral $\mathrm{WO}_{x}$ and surface acidity.

\subsection{Effect of calcination temperature}

Fig. S3 $\uparrow$ shows the XRD patterns of $8 \mathrm{~W} / \mathrm{SBA}-15$ prepared with different calcination temperatures. It is clear that more crystalline $\mathrm{WO}_{3}$ phase is present on the surface of SBA-15 support with increasing calcination temperature from 400 to 550 , and $700^{\circ} \mathrm{C}$ as reflected with the notable increase in diffraction peaks at $23.1,23.6,24.3$, and $34.1^{\circ}$; this is ascribed to the sintering of amorphous oligomeric octahedral $\mathrm{WO}_{x}$ species to form the crystalline $\mathrm{WO}_{3}$ at higher temperature. Similarly, Praserthdam et al. investigated the effects of calcination ramp rate and calcination temperature on the amount of crystalline $\mathrm{WO}_{3}$. It was shown that a lower calcination ramp rate could enhance the catalyst activity in metathesis reaction from ethylene and 2butene as compared to the ones calcined with a higher rate because they led to better dispersed catalysts. ${ }^{47}$ And the $\mathrm{WO}_{3}$ crystals were also clearly detected in XRD at a high calcination temperature. ${ }^{48}$ In our study, the speculated transformation of $\mathrm{W}$ phase is well confirmed by their UV-vis DRS spectra as shown in Fig. S4. $\dagger$ In detail, for $8 \mathrm{~W} / \mathrm{SBA}-15-700 \mathrm{C}$ catalyst, the relative intensity of band at $\sim 270 \mathrm{~nm}$ to that at $\sim 225 \mathrm{~nm}$ is substantially increased in contrast to that for $8 \mathrm{~W} / \mathrm{SBA}-15-400 \mathrm{C}$ and $8 \mathrm{~W} / \mathrm{SBA}-$ 15-550C catalysts. Also, a new pronounced band of crystalline $\mathrm{WO}_{3}$ at $\sim 400 \mathrm{~nm}$ for $8 \mathrm{~W} / \mathrm{SBA}-15-700 \mathrm{C}$ is detectable, which means that the increased content in crystalline $\mathrm{WO}_{3}$ mainly comes from the evolution of oligomeric octahedral $\mathrm{WO}_{x}$ species. Raman spectra for those prepared $8 \mathrm{~W} / \mathrm{SBA}-15$ catalysts also demonstrate that the content of crystalline $\mathrm{WO}_{3}$ increases with an increase in the calcination temperature (Fig. S5†).

It is somewhat curious that the abovementioned change of the state of $\mathrm{W}$ phase has negligible effect on the both isomerization of 1-butene and subsequent metathesis reaction as presented in Table S3. $\dagger$ It is worthy of note that, prior to catalytic reaction, the as-prepared $8 \mathrm{~W} / \mathrm{SBA}-15-400 \mathrm{C}$ is pretreated in a flow of $\mathrm{N}_{2}$ at $550{ }^{\circ} \mathrm{C}$. The pretreatment procedure may lead to no significant discrepancies between 8W/SBA-15-400C and 8W/ SBA-15-550C before the catalytic reaction. ${ }^{49}$ For 8 W/SBA-15550C and 8W/SBA-15-700C catalysts, the similar catalytic performance might be owing to their no distinct difference in the content for the isolated tetrahedral $\mathrm{WO}_{x}$ (Fig. S4†). These reasons are responsible for almost unchanged catalytic results for 1-butene conversion and products selectivity.

\subsection{Effect of W loading}

Table 1 shows the BET surface area, pore volume, pore size, and acidity for the SBA-15 supported $\mathrm{W}$ catalyst with different $\mathrm{W}$ loadings. The BET surface area and pore volume continuously decrease with an increase in the $\mathrm{W}$ loading due to the additional mass introduced by the supported $\mathrm{WO}_{x}$ phase. The reduced surface area possibly originates partially from bulky $\mathrm{WO}_{x}$ species blocking the pores of SBA-15. ${ }^{50}$ It also can be seen from
Fig. S6A $\dagger$ that all the samples exhibit the type IV isotherms with $\mathrm{H}_{1}$ hysteresis loops, which are typical for highly ordered hexagonal structure of mesoporous silica material. ${ }^{51}$ These results confirm the maintenance of ordered hexagonal arrangement of the SBA-15 frameworks upon $\mathrm{W}$ loading. Fig. S6B $\dagger$ shows the pure SBA-15 and its supported W samples have a narrow pore size distribution with an average size about $\sim 6 \mathrm{~nm}$. As the $\mathrm{W}$ loading increases from 4 to $30 \mathrm{wt} \%$, the surface density of $\mathrm{W}$ atoms is drastically enhanced from 0.18 to $2.84 \mathrm{~W} \mathrm{~nm}^{-2}$. Regarding the strength and types of acid sites, it can be determined from the pyridine adsorption measured by IR spectra (Fig. S7 $†$ ). As presented in Table 1, the acidity for both Brønsted acid and Lewis acid firstly increases and then decreases with a higher $\mathrm{W}$ loading and the $15 \mathrm{wt} \% \mathrm{~W}$ loading leads to the maximum acidity. Note that the pure SBA- 15 and a low $\mathrm{W}$ loading of $4 \mathrm{wt} \%$ do not indicate the presence of Brønsted acid. As shown in Fig. S7, $\dagger$ pure SBA-15 shows a band at $\sim 1445 \mathrm{~cm}^{-1}$ assigned to hydrogen-bonded pyridine $(\mathrm{H})$, indicating that the $\mathrm{H}$ band seems to be come from the pyridine hydrogen bonded to the Si-OH..$^{52}$ With a loading of $\mathrm{WO}_{3}$, a new band located at $\sim 1450 \mathrm{~cm}^{-1}$ formed is attributed to pyridine coordinately bonded to surface Lewis acid sites; these acid sites are ascribed to the isolated $\mathrm{WO}_{x}$ in the tetrahedral coordination. ${ }^{53}$ When the $\mathrm{WO}_{3}$ is loaded in $8 \mathrm{wt} \%$, a new band at $\sim 1540 \mathrm{~cm}^{-1}$ gradually appears, indicating the protonated pyridine bonded to surface Brønsted acid. The appearing surface Brønsted acid sites might be due to the protonation of terminal $\mathrm{W}$ sites in the tetrahedral coordination..$^{54}$ With continuously increasing $\mathrm{W}$ loading, both Brønsted acid and Lewis acid are decreased after reaching the maximum acidity with a loading of $15 \mathrm{wt} \%$; this is ascribed to the increased $\mathrm{WO}_{3}$ content leading to the formation of oligomeric species and further bulk $\mathrm{WO}_{3}$ species with lower content in the terminal $\mathrm{W}$ sites. To this end, we have clearly elucidated the type and content of acidity varied with the $\mathrm{WO}_{x}$ content.

In order to further confirm the evolution of $\mathrm{W}$ phase and its molecular bonding with different $\mathrm{W}$ loadings, the as-prepared supported $\mathrm{W}$ catalysts are characterized by XRD, Raman, and XPS. The XRD patterns of SBA-15 and its supported $\mathrm{W}$ catalysts are given in Fig. 3. It is clearly illustrated that the crystalline $\mathrm{WO}_{3}$ (PDF\#83-0948, triclinic) is present when the $\mathrm{WO}_{3}$ content is higher than $8 \mathrm{wt} \%$, which is different from that (PDF\# 721465 , monoclinic) for $8 \mathrm{~W} / \mathrm{SiO}_{2}$ sample (Fig. S1 $\dagger$ ). The intensity of diffraction peaks located at $2 \theta$ of $23.1,23.6,24.3$, and $33.6^{\circ}$ becomes stronger with an increase in the $\mathrm{WO}_{3}$ content, which suggests that a certain amount of crystalline $\mathrm{WO}_{3}$ appears. As presented in Fig. 4, the Raman spectra for above samples imply that the aggregated $\mathrm{WO}_{x}$ species including amorphous and crystalline $\mathrm{W}$ phase continuously increase with an increase in the $\mathrm{WO}_{3}$ content, as reflected with stronger bands at 274, 715, and $805 \mathrm{~cm}^{-1}$. The band at $\sim 980 \mathrm{~cm}^{-1}$ assigned to terminal $\mathrm{W}=\mathrm{O}$ bond firstly increases and then slightly decreases. The strongest band is present over $15 \mathrm{~W} / \mathrm{SBA}-15$ catalyst. This can be inferred that the concentration of highly dispersed $\mathrm{WO}_{x}$ species cannot be increased further, and the additional $\mathrm{W}$ loading contributes progressively to the growth of $\mathrm{WO}_{3}$ nanoparticles. ${ }^{26}$ XPS measurements are conducted to detect the oxidation state 
Table 1 Physicochemical properties of SBA-15 and W/SBA-15 catalysts with different W loadings

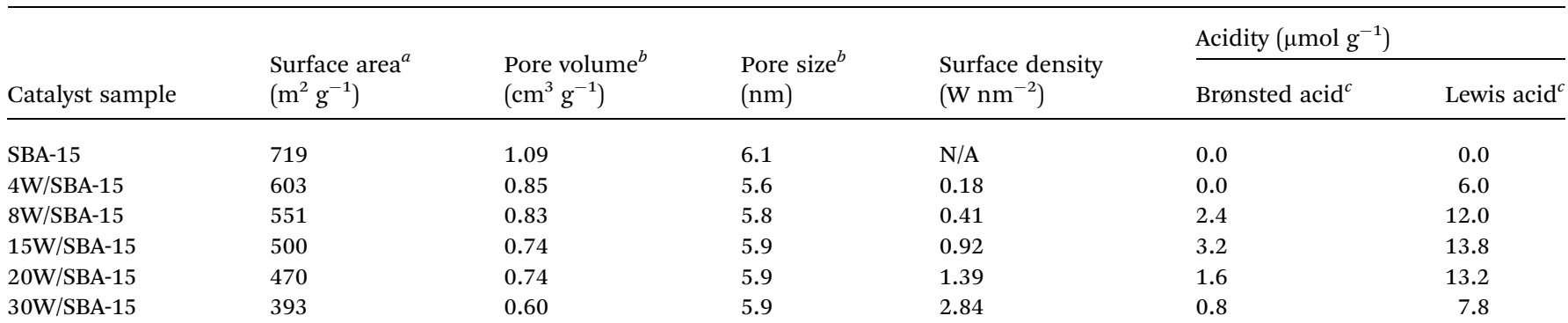

${ }^{a}$ Determined by BET method. ${ }^{b}$ Evaluated by the BJH method. ${ }^{c}$ Determined by pyridine-IR measurement.

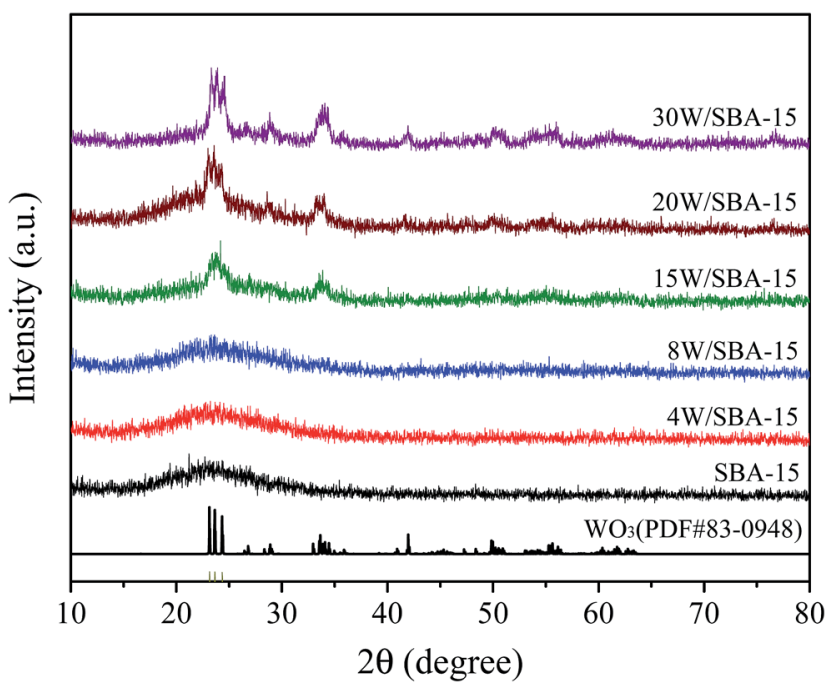

Fig. 3 XRD patterns of fresh SBA-15 and W/SBA-15 catalysts with different $\mathrm{W}$ loadings.

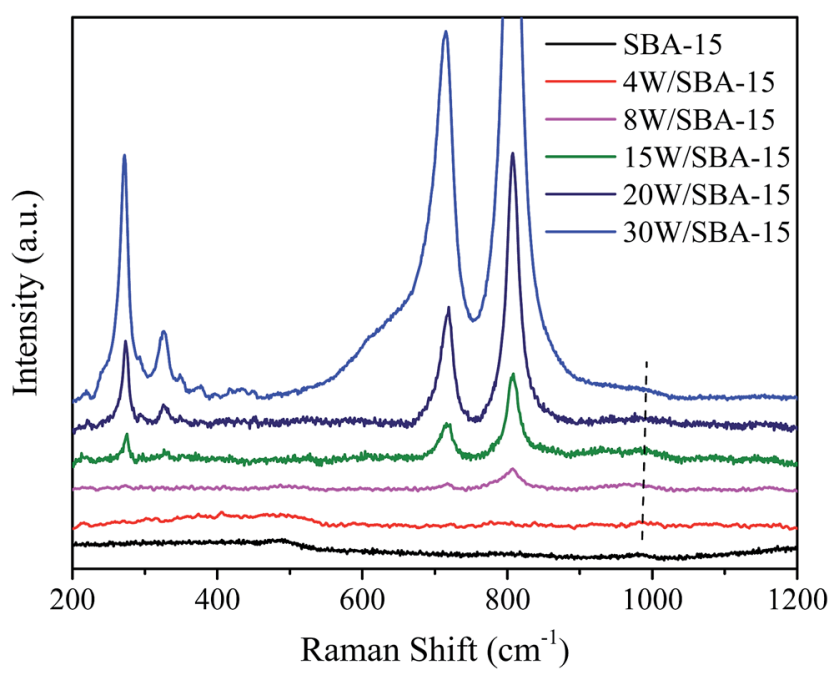

Fig. 4 Raman spectra of fresh SBA-15 and W/SBA-15 catalysts with different $\mathrm{W}$ loadings.

of surface $\mathrm{W}$ species. The XPS spectra of $\mathrm{W} 4 \mathrm{f}$ level are fitted according to the theory of Doniach and Sunjic. ${ }^{55}$ As shown in Fig. 5, the binding energy at $35.7 / 37.9 \mathrm{eV}$ and $36.2 / 38.1 \mathrm{eV}$ is ascribed to the $4 \mathrm{f}_{7 / 2}$ and $4 \mathrm{f}_{5 / 2}$ peaks of $\mathrm{W}$ atoms for aggregated $\mathrm{W}^{6+}$ oxide and dispersed $\mathrm{W}^{6+}$ hydroxide $\mathrm{WO}_{3}\left(\mathrm{OH}_{2}\right)_{n}$, respectively. ${ }^{56,57}$ As illustrated in literature, the $\mathrm{W}^{6+}$ hydroxide could be transformed to surface tetrahedral $\mathrm{WO}_{x}{ }^{58}$ The investigated catalysts of $4 \mathrm{~W} / \mathrm{SBA}-15,15 \mathrm{~W} / \mathrm{SBA}-15$, and $30 \mathrm{~W} / \mathrm{SBA}-15$ exhibit the peaks of $\mathrm{W}^{6+}$ hydroxide, its peaks intensity displays maxima over $15 \mathrm{~W} / \mathrm{SBA}-15$ catalyst, which can be explained that the isolated tetrahedral $\mathrm{WO}_{x}$ is active to absorb $\mathrm{H}_{2} \mathrm{O}$ molecules in air for the formation of $\mathrm{WO}_{3}\left(\mathrm{OH}_{2}\right)_{n}$. This result further confirms that $15 \mathrm{~W} / \mathrm{SBA}-15$ has the highest content of isolated $\mathrm{WO}_{x}$.

The catalytic performance over SBA-15 supported $\mathrm{W}$ catalysts with different loadings is summarized in Fig. 6 and Table S4. $\dagger$ The pure SBA-15 exhibits a stable 1-butene conversion of $72.3 \%$ with a negligible selectivity to propene. The 1-butene is mainly converted into trans-2-butene and cis-2-butene via $\mathrm{C}=\mathrm{C}$ bond isomerization, which suggests that the $\mathrm{Si}-\mathrm{OH}$ in SBA- 15 has the isomerization activity. ${ }^{52} \mathrm{As} \mathrm{W}$ is introduced to SBA-15 with a $4 \mathrm{wt} \%$ loading, the selectivity to propene is notably enhanced from 2.9 to $37.4 \%$, however, the 1-butene conversion increases slightly from 72.3 to $78.9 \%$ (Table S4 $\dagger$ ). This result reflects that the isolated $\mathrm{WO}_{x}$ of tetrahedral coordination is responsible for the metathesis reaction to produce propene. With further

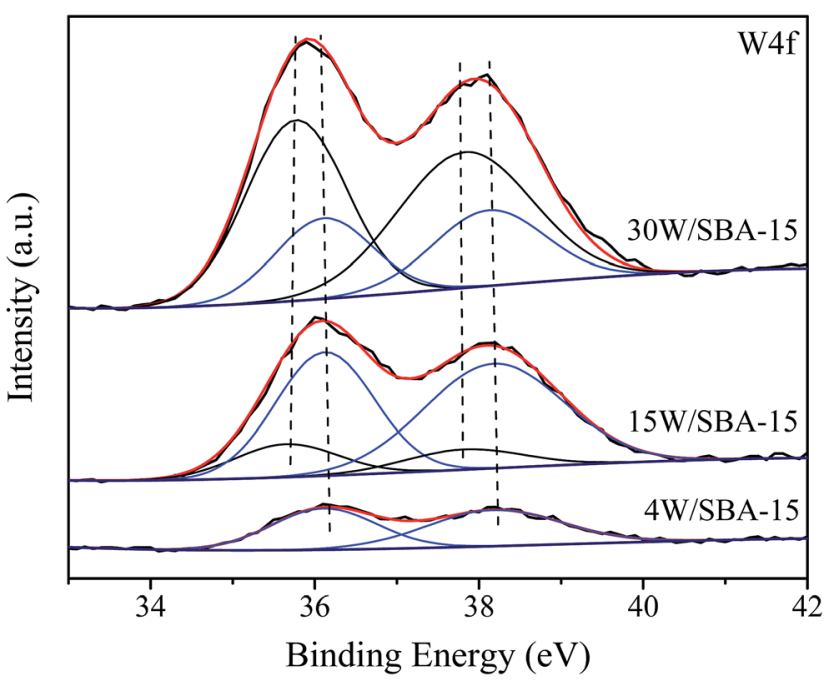

Fig. 5 XPS spectra of fresh 4W/SBA-15, 15W/SBA-15, and 30W/SBA15 catalysts. 

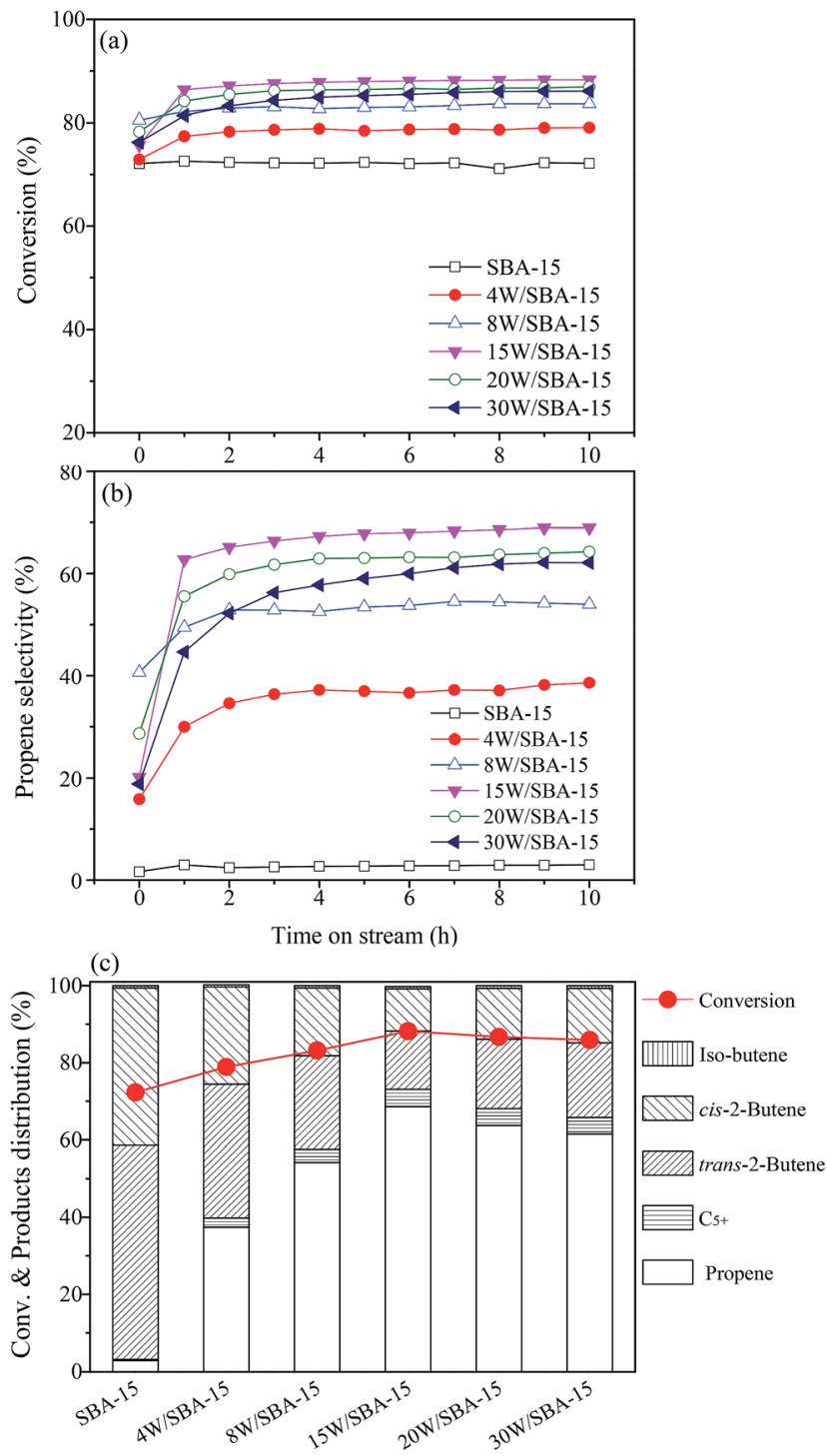

Fig. 6 Time-dependence of 1-butene conversion (a), propene selectivity (b), and products distribution (c) obtained over SBA-15 and W/SBA-15 catalysts with different $W$ loadings at the reaction conditions of $450{ }^{\circ} \mathrm{C}, 0.1 \mathrm{MPa}, 0.5 \mathrm{~g}$ of catalyst weight, $1.8 \mathrm{~h}^{-1}$ of WHSV, and an ethylene/1-butene molar ratio of 2 .

increase in $\mathrm{W}$ loading from 4,8 to $15 \mathrm{wt} \%$, the 1-butene conversion continuously increases to a small extent from 78.9, 83.3 , to $88.2 \%$. Accordingly, the selectivity to propene increases remarkably from $37.4,54.6$, to $68.6 \%$ with marked increase in Brønsted acidity (Table 1). The above discussion demonstrates that both Lewis and Brønsted acid sites from the isolated tetrahedral $\mathrm{WO}_{x}$ structure are favorable for the metathesis reaction. When $\mathrm{W}$ is introduced over a suitable amount, for example $15 \mathrm{wt} \%$, both 1-butene conversion and selectivity to propene are decreased. In contrast, the metathesis activity is reduced to a larger extent. This is ascribed to the less amount of the formation of isolated tetrahedral $\mathrm{WO}_{x}$ structure which results from its evolution into the inactive crystalline $\mathrm{WO}_{3}$.

In order to investigate the evolution of SBA-15 supported W catalysts during the catalytic reaction, the fresh and spent catalysts are characterized by UV-vis DRS spectra as presented in Fig. S8. $\dagger$ It is clear that the intensity of band at $\sim 225 \mathrm{~nm}$ gradually increases to a stable level when $\mathrm{W}$ loading is below $15 \mathrm{wt} \%$, which is attributed to the increased content for the isolated tetrahedral $\mathrm{WO}_{x}$ structure during the catalytic reaction. In addition, all spent catalysts exhibit gradually increased intensity of the band in the range of 400 to $700 \mathrm{~nm}$. The higher W content supported on SBA-15, the more markedly elevated band intensity. This band is assigned to the $\mathrm{W}^{4+}$ and $\mathrm{W}^{5+}$ species. ${ }^{17}$ The lower oxidation state of $\mathrm{W}$ species is due to the reduction of $\mathrm{W}^{6+}$ during the reaction. To further confirm the presence of lower oxidation state of $\mathrm{W}$ species, the spent $15 \mathrm{~W} /$ SBA-15 catalysts with different reaction time are measured by $\mathrm{XRD}$ as displayed in Fig. 7. One can see that the diffraction peak at $2 \theta$ of $33.6^{\circ}$ assigned to crystalline $\mathrm{WO}_{3}$ is gradually shifted to lower value at $33.3^{\circ}$ due to the appearance of nonstoichiometric phase $\mathrm{WO}_{2.92}$ and $\mathrm{WO}_{2.83}$, which suggests that the tungsten oxide species are gradually reduced during the metathesis reaction. It can be inferred that the reduction of $\mathrm{W}$ catalysts might be closely related to the induction period. ${ }^{59}$ As shown in Fig. S9, $\dagger$ the TPR profiles of fresh $8 \mathrm{~W} / \mathrm{SBA}-15,15 \mathrm{~W} / \mathrm{SBA}-15$, and 30W/SBA-15 catalysts display three typical reduction peaks for $\mathrm{WO}_{3}$ to $\mathrm{WO}_{2.90}, \mathrm{WO}_{2.90}$ to $\mathrm{WO}_{2}$, and $\mathrm{WO}_{2}$ to $\mathrm{W}$, respectively. ${ }^{60}$ The temperature range for three different reduction stages is located at $400-500,630-740$, and $740-880^{\circ} \mathrm{C}$, respectively. This result further demonstrates that the tungsten oxide species could be reduced at the reaction temperature of $450{ }^{\circ} \mathrm{C}$ during metathesis reaction.

\subsection{Effect of pretreatment gas}

The catalytic performance for $15 \mathrm{~W} / \mathrm{SBA}-15$ pretreated with different gases is presented in Fig. 8 and Table 2. In contrast to $\mathrm{N}_{2}$-pretreated $15 \mathrm{~W} / \mathrm{SBA}-15$ previously described as a reference, $\mathrm{H}_{2}$-pretreatment does not significantly affect the 1-butene conversion, however, the induction period becomes shorter to

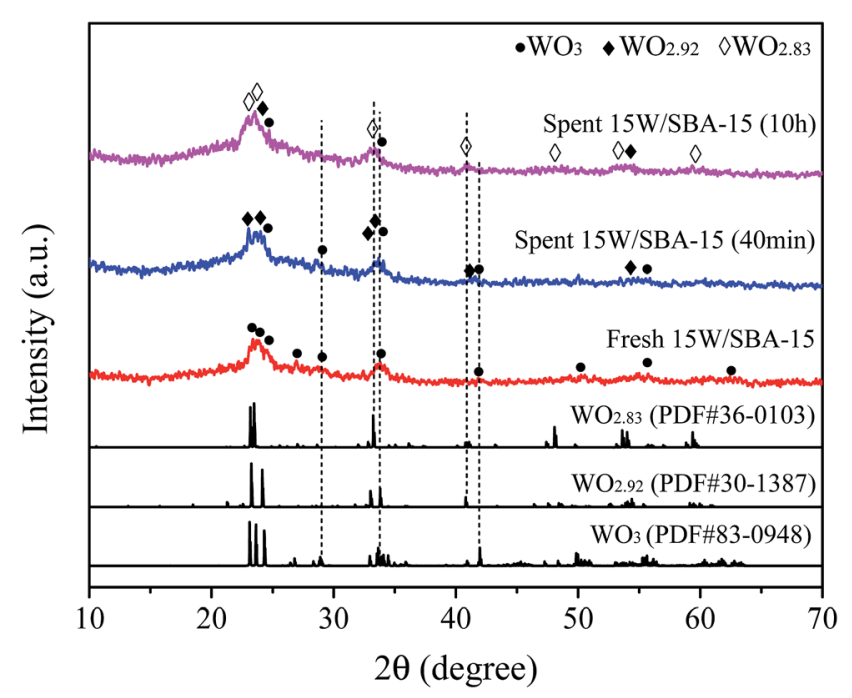

Fig. 7 XRD patterns of fresh 15W/SBA-15 and two spent catalysts recovered after $40 \mathrm{~min}$ and $10 \mathrm{~h}$ of reaction, respectively. 

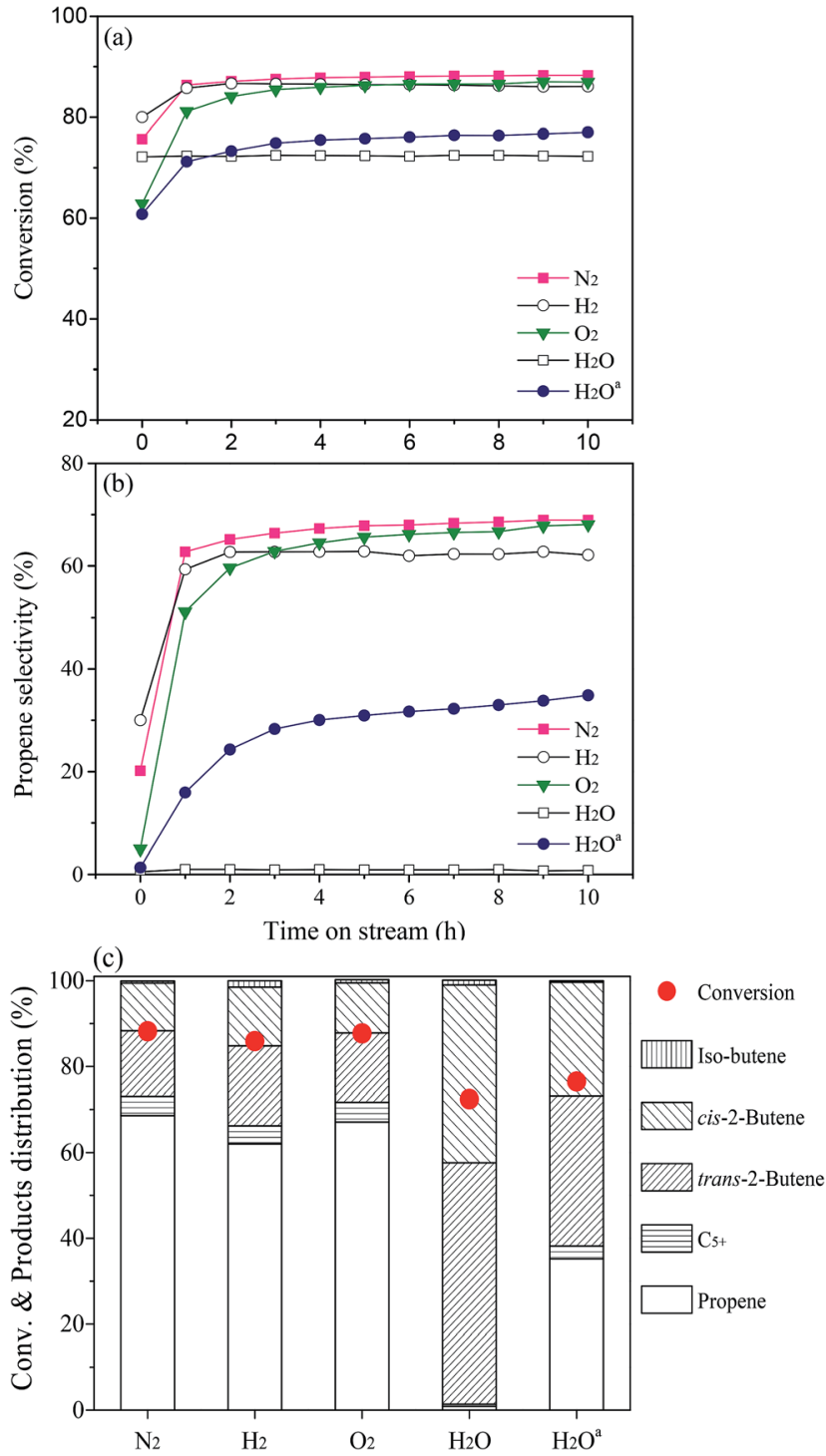

Fig. 8 Time-dependence of 1-butene conversion (a), propene selectivity (b), and products distribution (c) over 15W/SBA-15 catalysts pretreated in different gases at the reaction conditions of $450{ }^{\circ} \mathrm{C}$, $0.1 \mathrm{MPa}, 0.5 \mathrm{~g}$ of catalyst weight, $1.8 \mathrm{~h}^{-1}$ of WHSV, and an ethylene/1butene molar ratio of 2 . ${ }^{a}$ Spent $15 \mathrm{~W} / \mathrm{SBA}-15$ catalyst pretreated in $\mathrm{H}_{2} \mathrm{O}$ followed by calcination, and the obtained catalyst further treated in $\mathrm{N}_{2}$ stream before reaction. result in a higher initial selectivity to propene at 30\% compared with that for $\mathrm{N}_{2}$-pretreatment at $20 \%$. For $15 \mathrm{~W} / \mathrm{SBA}-15$ pretreated by $1 \% \mathrm{O}_{2} / \mathrm{N}_{2}$ gas, the 1-butene conversion is still kept unchanged. This indicates that the 1-butene isomerization is not closely related to the state of $\mathrm{WO}_{x}$. As expected, the initial selectivity to propene obtained in metathesis reaction is significantly lower at 5\% and need a longer time to reach the stable stage. The abovementioned result analysis strongly demonstrates that the partially reduced $\mathrm{WO}_{x}$ species is necessary precursor for the formation of active sites for metathesis reaction, but not for 1-butene isomerization. Liu et al. also confirmed that the partially reduced $\mathrm{WO}_{2.92}$ as active phase for metathesis reaction by adjusting the $\mathrm{H}_{2}$ concentration in prior reduction process. ${ }^{61}$ It is no doubt that the extent of reduction influences the metathesis activity as previously mentioned. However, it is hard to correlate the metathesis activity with quantifying the content of reduced $\mathrm{WO}_{x}$ species. Indeed, without prior reduction process, the active sites for metathesis reaction are generated by the interaction of olefins with W/SBA15 catalyst during the reaction, which takes more time for subsequent formation of propene.

Interestingly, the pretreatment with water vapor introduced by a flowing $\mathrm{N}_{2}$ leads to the complete deactivation of metathesis reaction (Fig. 8b), however, the isomerization activity is similar to that for pure SBA-15 support (Fig. 6a). Furthermore, the spent $\mathrm{H}_{2} \mathrm{O}$-pretreated $15 \mathrm{~W} / \mathrm{SBA}-15$ catalyst is calcined in air at $550{ }^{\circ} \mathrm{C}$ like the preparation procedure for fresh catalyst. The obtained sample is re-evaluated using the same reaction conditions with the fresh $\mathrm{N}_{2}$-pretreated catalyst, which has not fully recovered the catalytic performance for 1-butene conversion and selectivity to propene. This result indicates that $\mathrm{H}_{2} \mathrm{O}$-pretreatment seriously alters the existing structure of $\mathrm{WO}_{x}$ species (Fig. 9a). For comparison, the XRD patterns for spent $\mathrm{N}_{2^{-}}, \mathrm{H}_{2^{-}}$, and $\mathrm{O}_{2^{-}}$ pretreated $15 \mathrm{~W} / \mathrm{SBA}-15$ catalysts do not exhibit obvious evolution for tungsten oxide species (Fig. 9b). On the other hand, the diffraction peaks for $\mathrm{H}_{2} \mathrm{O}$-pretreated $15 \mathrm{~W} / \mathrm{SBA}-15$ catalyst illustrate the presence of large amount of crystalline $\mathrm{WO}_{3}$ phase. These intensive peaks are located at 23.1, 23.6, 24.3, and 33.3 ${ }^{\circ}$, which represent the monoclinic $\mathrm{WO}_{3}$ similar to that for $8 \mathrm{~W} / \mathrm{SiO}_{2}$ (Fig. S1 $\dagger$ ). XPS spectra of fresh $15 \mathrm{~W} / \mathrm{SBA}-15$ and $\mathrm{H}_{2} \mathrm{O}$-pretreated 15W/SBA-15 catalysts are presented in Fig. S10. $\dagger$ In the case of $\mathrm{H}_{2} \mathrm{O}$-pretreated $15 \mathrm{~W} / \mathrm{SBA}-15$ catalyst, the peaks intensity of binding energy at 35.7 and $37.9 \mathrm{eV}$ (black line) substantially

Table 2 Catalytic performance of $15 \mathrm{~W} / \mathrm{SBA}-15$ catalyst pretreated in different gases at $550{ }^{\circ} \mathrm{C}$

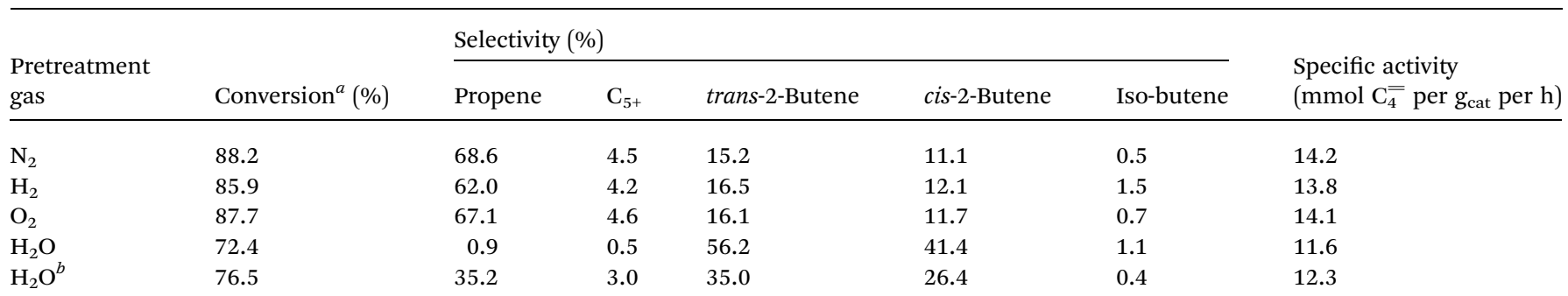

${ }^{a}$ Reaction conditions: $T=450{ }^{\circ} \mathrm{C}, P=0.1 \mathrm{MPa}$, catalyst weight $=0.5 \mathrm{~g}$, WHSV $(\mathrm{E}+\mathrm{B})=1.8 \mathrm{~h}^{-1}, n(\mathrm{E}) / n(\mathrm{~B})=2 .{ }^{b}$ Spent $15 \mathrm{~W} / \mathrm{SBA}-15$ catalyst pretreated in $\mathrm{H}_{2} \mathrm{O}$ followed by calcination, and the obtained catalyst further treated in $\mathrm{N}_{2}$ stream before reaction. 

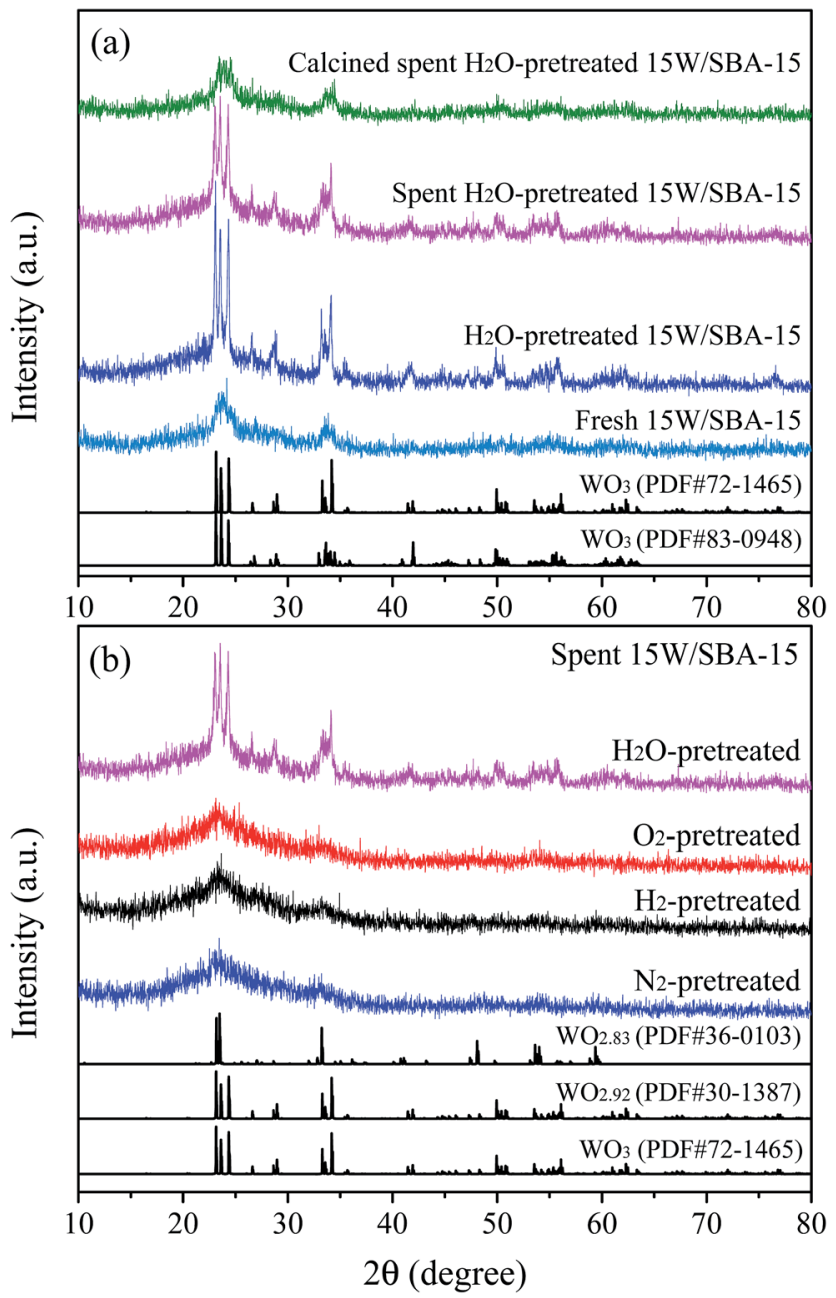

Fig. 9 XRD patterns of (a) fresh 15W/SBA-15, $\mathrm{H}_{2} \mathrm{O}$-pretreated 15W/ SBA-15, spent $\mathrm{H}_{2} \mathrm{O}$-pretreated 15W/SBA-15, calcined spent $\mathrm{H}_{2} \mathrm{O}$ pretreated $15 \mathrm{~W} / \mathrm{SBA}-15$, and (b) spent $15 \mathrm{~W} / \mathrm{SBA}-15$ catalysts pretreated in different gases $\left(\mathrm{N}_{2}, \mathrm{H}_{2}, \mathrm{O}_{2}\right.$ and $\left.\mathrm{H}_{2} \mathrm{O}\right)$.

increases, which suggests that the content for aggregated $\mathrm{W}^{6+}$ oxide increases. Correspondingly, the peaks intensity of binding energy at 36.2 and $38.1 \mathrm{eV}$ (blue line) decrease to a remarkable extent with the decreased content for $\mathrm{W}^{6+}$ hydroxide $\mathrm{WO}_{3}\left(\mathrm{OH}_{2}\right)_{n}$. Despite that $\mathrm{WO}_{3}\left(\mathrm{OH}_{2}\right)_{n}$ still exists, the $\mathrm{H}_{2} \mathrm{O}$-pretreated 15W/SBA-15 catalyst does not display metathesis activity. This is ascribed to the remaining presence of $\mathrm{H}_{2} \mathrm{O}$ molecules at the surface of catalyst to be unfavorable for the transformation of $\mathrm{WO}_{3}\left(\mathrm{OH}_{2}\right)_{n}$ into active sites for metathesis reaction. In order to clarify the influence of $\mathrm{H}_{2} \mathrm{O}$ on the catalyst evolution, the $\mathrm{H}_{2}$-TPR experiments for fresh 15W/SBA-15 and calcined spent $\mathrm{H}_{2} \mathrm{O}$-pretreated $15 \mathrm{~W} / \mathrm{SBA}-15$ catalysts are carried out. As presented in Fig. S11, $\dagger$ the first reduction peak at the range of $400-500{ }^{\circ} \mathrm{C}$ shifts to higher temperature range and the peak intensity becomes much weaker. This result shows that the $\mathrm{H}_{2} \mathrm{O}$ pretreatment seriously affects the reducibility of tungsten oxide species. As previously demonstrated, the reduction behavior does really play an important role in forming the active sites for metathesis reaction. In our viewpoint, on the one hand, the catalyst pretreated by $\mathrm{H}_{2} \mathrm{O}$ leads to the irreversible deactivation due to the sintering of $\mathrm{WO}_{x}$ species; on the other hand, the remaining presence of $\mathrm{H}_{2} \mathrm{O}$ may also poison the reduced $\mathrm{W}^{5+}$ sites to be interacted with olefins for further $\mathrm{W}$ carbene formation. Although the catalyst was further flushed with inert $\mathrm{N}_{2}$ at relatively high temperature of $450{ }^{\circ} \mathrm{C}$ before the reaction, the metathesis reaction cannot proceed.

\subsection{Effect of WHSV of ethylene and 1-butene}

In order to obtain the optimal catalytic performance for the metathesis reaction of ethylene and 1-butene over 15W/SBA-15 catalyst, we have investigated the influence of WHSV of mixed feed gas in a fixed-bed reactor. The catalytic performances are evaluated by 1-butene conversion, specific activity and product selectivity. Note that the specific activity is defined as the converted amount of 1-butene in molar base per gram of catalyst per hour. In our study, the WHSV was regulated by changing the loaded amount of catalyst with a constant flow

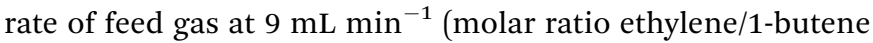
$=2 / 1$ ). As presented in Fig. S12 $\dagger$ and Table 3, the $0.25 \mathrm{~g}$ of $15 \mathrm{~W} / \mathrm{SBA}-15\left(\mathrm{WHSV}=3.6 \mathrm{~h}^{-1}\right.$ ) leads to the lowest 1-butene conversion and remarkably lower selectivity to propene but the highest specific activity at $25.7 \mathrm{mmol} \mathrm{C}_{4}^{\bar{y}}$ per $\mathrm{g}_{\text {cat }}$ per h. The 1butene conversion and selectivity to propene reach the maximum value at $91.2 \%$ and $75.8 \%$ with a WHSV of $0.9 \mathrm{~h}^{-1}$, respectively. Accordingly, the specific activity is about $7.4 \mathrm{mmol} \mathrm{C}_{4}^{\overline{ }}$ per $\mathrm{g}_{\text {cat }}$ per $\mathrm{h}$, which is higher than the value of $6.4 \mathrm{mmol} \mathrm{C}_{4}^{\overline{ }}$ per $\mathrm{g}_{\text {cat }}$ per $\mathrm{h}$ for W-FDU-12 combined with $\mathrm{MgO}$ catalysts under the similar reaction conditions. ${ }^{33}$ However, the overloaded catalyst $\left(1.5 \mathrm{~g}\right.$, WHSV $\left.=0.6 \mathrm{~h}^{-1}\right)$ slightly decreases both 1-butene conversion and selectivity to propene with the lowest specific activity at $4.8 \mathrm{mmol} \mathrm{C}_{4}^{\bar{y}}$ per $\mathrm{g}_{\text {cat }}$ per $\mathrm{h}$. On the basis of above catalytic results, the insufficient loaded catalyst exhibits much lower selectivity to propene, which suggests that the reaction rate of metathesis step is slower than that for isomerization step. In other words, the isomerized 2-butene could not be quickly converted into propene via metathesis reaction. This conclusion can also be obtained from the changing trend of 1-butene conversion, propene selectivity, and specific activity as listed in Table 3. As the WHSV is raised to a much higher value at $3.6 \mathrm{~h}^{-1}$, the 1-butene conversion decreases slightly while the selectivity to propene drops remarkably from 72.7 to $40.6 \%$. Seen from the specific activity listed, the high WHSV of $3.6 \mathrm{~h}^{-1}$ exhibits about 5 times higher value than that for $0.6 \mathrm{~h}^{-1}$. This result also indicates that the conversion rate of 1-butene is quite fast. The metathesis reaction is rate-determining step for the enhancing selectivity to propene. In the case of overloaded catalyst, the selectivity to propene is decreased due to the reversible conversion between propene, 2-butene, and 1-butene. ${ }^{35}$ As the formed propene could not be run away from the catalyst surface, it will return back to 2-butene and ethylene. It is worth noting that a longer residence time (lower WHSV) gradually enhances the skeletal isomerization of 1-butene, despite that it is more difficult to proceed than that for $\mathrm{C}=\mathrm{C}$ bond isomerization. ${ }^{40}$ Therefore, a suitable WHSV is necessary to obtain the high selectivity to propene. 
Table 3 Catalytic performance of 15W/SBA-15 catalyst at different WHSV

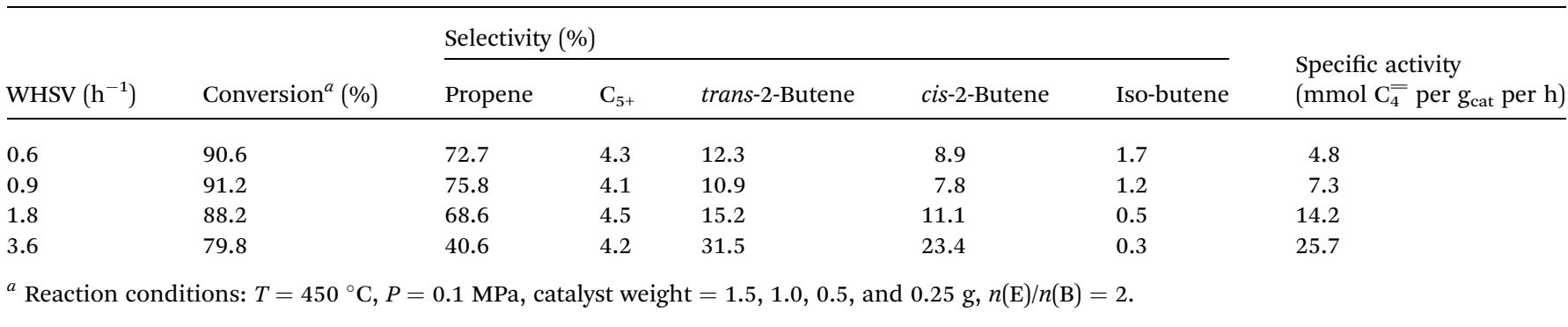

\subsection{Effect of reaction temperature}

Finally, the reaction temperature is regulated to optimize the catalytic performance over $15 \mathrm{~W} / \mathrm{SBA}-15$ catalyst under the above optimal WHSV of $0.9 \mathrm{~h}^{-1}$. As can be seen from Fig. S13† and Table 4, the lower reaction temperature gives slightly lower 1butene conversion but significantly lower selectivity to propene. The decreased trend in 1-butene conversion is much milder than that for propene selectivity, which illustrates that the metathesis reaction is more difficult to occur relative to the isomerization reaction of 1-butene. The optimal selectivity to propene at $79.1 \%$ with 1 -butene conversion of $92.1 \%$ is obtained over the reaction temperature of $500{ }^{\circ} \mathrm{C}$. When the reaction temperature is further elevated to $550^{\circ} \mathrm{C}$, in spite of the stable 1-butene conversion, the selectivity to propene is obviously decreased due to the formation of $\mathrm{C}_{1}-\mathrm{C}_{3}$ alkane from thermal-cracking. ${ }^{62}$ Thereby, the suitable reaction temperature should be selected to obtain the highest selectivity to propene through efficient conversion of the formed intermediate 2butene into propene via metathesis reaction, and avoid the sidereactions such as skeletal isomerization and thermal-cracking.

\subsection{Discussion on mechanism of metathesis reaction}

Based on above experimental results combined with various characterizations such as XRD, UV-vis DRS, Raman, pyridine IR, and $\mathrm{H}_{2}$-TPR, it is well confirmed that the partially reduced isolated tetrahedral $\mathrm{WO}_{x}$ species can be responsible for subsequent metathesis reaction of 1-butene and ethylene.

When the 1-butene and ethylene are used as reactants for producing propene via metathesis reaction, there are three steps involved including (1) fast isomerization of 1-butene, (2) carbene formation, and (3) metathesis reaction as shown in Scheme 1. It is no doubt that SBA-15 exhibits significant isomerization activity, which is catalyzed by $\mathrm{Si}-\mathrm{OH}$ (Scheme 1, 1). The Si-OH might be working as a weak Brønsted acid site for isomerization of $\mathrm{C}=\mathrm{C}$ bond, however, lack of ability of metathesis. ${ }^{63}$ Table S4† shows that the varied $\mathrm{W}$ loadings do not affect the level of 1-butene conversion in spite of the less amount of Si-OH on W/SBA-15 with well dispersed $\mathrm{W}$ over the support. As noted in the previous description, the isomerization rate of 1-butene is so fast that the decrease in the amount of $\mathrm{Si}-$ $\mathrm{OH}$ could not suppress the 1-butene isomerization. It is important to note that unsupported $\mathrm{WO}_{3}$ displays the negligible activity for 1-butene isomerization and inactive in metathesis reaction. The previously mentioned results suggest that the isolated tetrahedral $\mathrm{WO}_{x}\left(\mathrm{~W}^{6+}\right)$ species can be reduced by olefin or $\mathrm{H}_{2}$ to form the $\mathrm{W}^{5+}$ species, which might be regarded as the pre-requisite step for subsequent formation of $\mathrm{W}$-carbene (Scheme 1, 2). Indeed, this viewpoint is strongly supported by following experimental facts: (1) shorter induction period for formation of propene after the catalyst pretreated in $\mathrm{H}_{2}$ stream; (2) pretreatment with $\mathrm{O}_{2}$ results in lower initial selectivity to propene (Fig. 8); (3) observed presence of $\mathrm{W}^{5+}$ in spent catalysts from UV-vis DRS spectra and XRD patterns (Fig. 7 and S8†) compared to fresh catalyst with only $\mathrm{W}^{6+}$ species (Fig. 5). It should be noted that the pretreatment with $\mathrm{H}_{2} \mathrm{O}$ directly deactivates the metathesis activity completely. The deactivation of catalyst might mainly result from the $\mathrm{H}_{2} \mathrm{O}$-induced aggregation of isolated $\mathrm{WO}_{x}$ species as the strong diffraction peaks for inactive $\mathrm{WO}_{3}$ phase are observed before and after reaction (Fig. 9a). However, the metathesis activity could be recovered to some extent due to the resulting re-dispersion of aggregated $\mathrm{WO}_{3}$ phase by calcination treatment. ${ }^{58}$ As reflected in Fig. 9a, the calcined spent $\mathrm{H}_{2} \mathrm{O}$-pretreated 15W/SBA-15 exhibits much weaker diffraction peaks for crystalline $\mathrm{WO}_{3}$ phase compared to that before calcination treatment. In spite of the proposed route

Table 4 Catalytic performance of 15W/SBA-15 catalyst at different reaction temperatures

\begin{tabular}{|c|c|c|c|c|c|c|c|}
\hline & Conversion $^{a}(\%)$ & \multicolumn{5}{|c|}{ Selectivity (\%) } & $\begin{array}{l}\text { Specific activity } \\
\left(\mathrm{mmol} \mathrm{C}_{4}^{=} \text {per } \mathrm{g}_{\text {cat }} \text { per } \mathrm{h}\right)\end{array}$ \\
\hline 400 & 84.6 & 49.5 & 4.2 & 26.0 & 18.6 & 1.7 & 6.8 \\
\hline 450 & 91.2 & 75.8 & 4.1 & 10.9 & 7.8 & 1.2 & 7.3 \\
\hline 500 & 92.1 & 79.1 & 3.8 & 8.7 & 6.5 & 1.9 & 7.4 \\
\hline
\end{tabular}



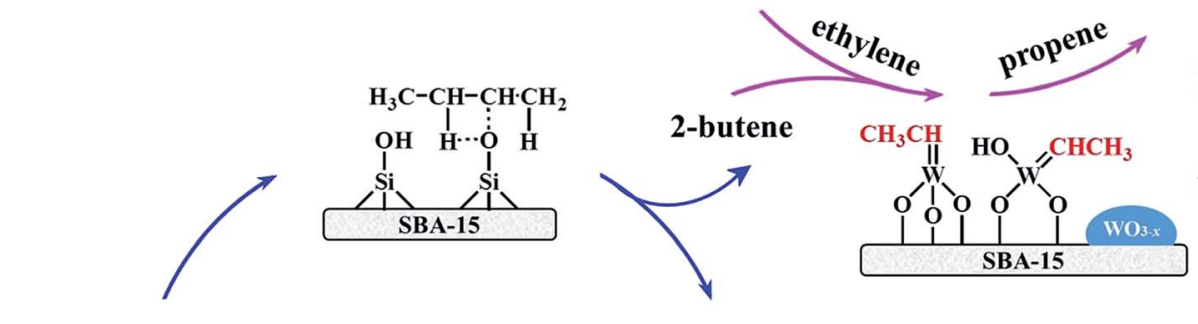

\section{Metathesis}

3
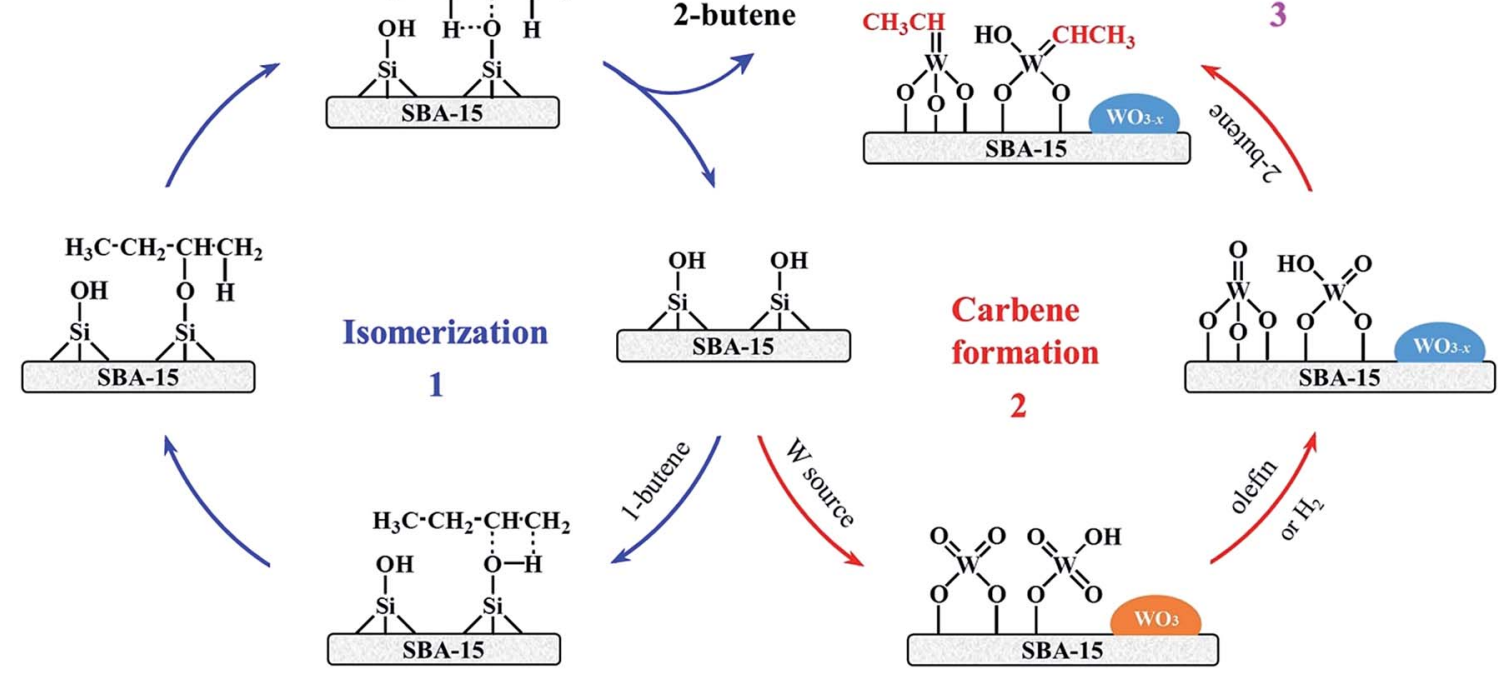

2

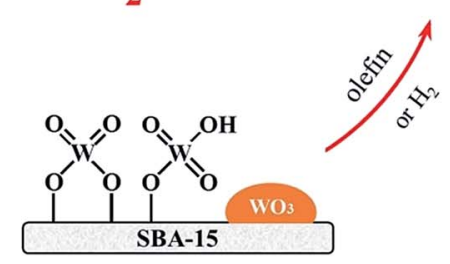

Scheme 1 Proposed route for conversion of 1-butene and ethylene into propene via isomerization (1), carbene formation (2), and metathesis reaction (3) over SBA-15 supported W catalysts.

for formation of W-carbene, we cannot deny that the isolated tetrahedral $\mathrm{W}^{6+}$ species possibly play a similar role like $\mathrm{W}^{5+}$ species.

The abovementioned isolated tetrahedral $\mathrm{W}^{5+}$ species consist of two types of structure, such as the terminal $\mathrm{W}=\mathrm{O}$ (Lewis acid sites) and $\mathrm{W}-\mathrm{OH}$ (Brønsted acid sites). It should be noted that these acid sites are possible to catalyze $\mathrm{C}=\mathrm{C}$ bond isomerization. ${ }^{64}$ The widely accepted olefin metathesis mechanism involves metallocarbene intermediates, implying that the successful activation of supported-oxide based olefin metathesis catalysts requires the conversion of $\mathrm{W}=\mathrm{O}$ and $\mathrm{W}-\mathrm{OH}$ species into $\mathrm{W}$-carbene. ${ }^{65,66}$ The formation pathways of $\mathrm{W}$-carbene over W/SBA-15 catalysts are illustrated in Scheme S1. $\dagger$ According to the DFT calculation, the 2-butene preferentially forms W-carbene active sites. ${ }^{67}$ In the case of terminal $\mathrm{W}=\mathrm{O}$, the $\mathrm{W}=\mathrm{O}$ is firstly combined with 2-butene by [2+2] cycloaddition reaction to form a four-membered oxametallacycle intermediate. Subsequently, the decomposition of the four-membered oxametallacycle intermediate produces the acetaldehyde $\left(\mathrm{H}_{3} \mathrm{C}-\mathrm{CH}=\mathrm{O}\right)$ and the final $\mathrm{W}=\mathrm{CH}-\mathrm{CH}_{3}$ active sites (Scheme $\mathrm{S} 1 \mathrm{~A} \dagger$ ). For the terminal $\mathrm{W}$-OH, the 2-butene is reacted with $\mathrm{W}-\mathrm{OH}$ to form 2-butanoxide by protonation reaction. Then, $\beta-\mathrm{H}$ in 2-butanoxide is combined with $\mathrm{W}=\mathrm{O}$ to form the six-membered oxametallacycle intermediate which can decompose into the four-membered oxametallacycle intermediate and $\mathrm{W}-\mathrm{OH}$ via migration of hydrogen from 2-butene to $\mathrm{W}=\mathrm{O}$. Also, subsequent elimination of carbonyl compound $\left(\mathrm{H}_{3} \mathrm{C}-\mathrm{CH}=\mathrm{O}\right)$ from the intermediate occurs to form $\mathrm{W}=\mathrm{CH}-\mathrm{CH}_{3}$ active sites (Scheme $\mathrm{S} 1 \mathrm{~B} \dagger$ ). The above $\mathrm{W}$ carbene formed via both the terminal $\mathrm{W}=\mathrm{O}$ and $\mathrm{W}-\mathrm{OH}$ is regarded as the active sites for metathesis reaction.

The postulated metathesis mechanism for the formation of propene is presented in Scheme S2. $\dagger$ It is clear that the initially formed $\mathrm{W}=\mathrm{CH}-\mathrm{CH}_{3}$ active sites can react with ethylene (Scheme S2a †) and 1-butene (Scheme S2bi) to give the metallocyclobutane intermediates by [2+2] cycloaddition reaction. ${ }^{68,69}$ Subsequently, these intermediates can be decomposed into propene with generation of new $\mathrm{W}$-carbene, such as $\mathrm{W}=$ $\mathrm{CH}_{2}$ and $\mathrm{W}=\mathrm{CH}-\mathrm{CH}_{2} \mathrm{CH}_{3}$. The newly generated $\mathrm{W}=\mathrm{CH}_{2}$ and $\mathrm{W}=\mathrm{CH}-\mathrm{CH}_{2} \mathrm{CH}_{3}$ further provide the active sites for cycloaddition with 2-butene to result in the metallocyclobutane intermediates. Similarly, the propene and 2-pentene are liberated from the metallocyclobutane intermediates with re-generation of initial $\mathrm{W}=\mathrm{CH}-\mathrm{CH}_{3}$ active sites. To this end, the metathesis reaction process for conversion of 1-butene and ethylene into propene has been fully elucidated in this study.

\section{Conclusions}

The investigation of the structure of tungsten oxide supported on SBA-15 and its catalytic performance in the metathesis reaction of 1-butene and ethylene to propene has been carried out extensively. The main conclusions are summarized as following several aspects.

For converting 1-butene and ethylene into propene, the 1butene is firstly required to be isomerized to 2-butene. The results show the $\mathrm{Si}-\mathrm{OH}$ serving as the primary active centers for 1-butene isomerization. And the terminal $\mathrm{W}=\mathrm{O}$ (Lewis acid sites) and $\mathrm{W}-\mathrm{OH}$ (Brønsted acid sites) in the isolated tetrahedral $\mathrm{WO}_{x}$ species might also play a role in the isomerization reaction. Over investigated W/SBA-15 catalysts, the isolated tetrahedral $\mathrm{WO}_{x}\left(\mathrm{~W}^{6+}\right)$ species are partially reduced by olefins or $\mathrm{H}_{2}$ to give rise to $\mathrm{WO}_{x}\left(\mathrm{~W}^{5+}\right)$ species as the precursor sites for the formation of W-carbene species which does contribute to olefin metathesis activity. In comparison to the isolated $\mathrm{WO}_{x}$ species, the crystalline $\mathrm{WO}_{3}$ phase does not show the metathesis activity despite that they are partially reduced during the reaction.

The W/SBA-15 catalysts exhibit different initial selectivity to propene with tuning pretreatment atmosphere. The reducing 
gas $\mathrm{H}_{2}$ results in a shorter induction time compared to that for inert gas $\mathrm{N}_{2}$ and oxidizing gas $\mathrm{O}_{2}$, which provides strong evidence that the partially reduced isolated $\mathrm{WO}_{x}\left(\mathrm{~W}^{5+}\right)$ species is crucial for the subsequent generation of W-carbene. It is further confirmed by $\mathrm{H}_{2} \mathrm{O}$ pretreatment as the suppressed reduction of $\mathrm{WO}_{x}$ species results in complete loss of metathesis activity. The sintering of isolated $\mathrm{WO}_{x}$ species leads to a significant increase in the crystalline $\mathrm{WO}_{3}$ content, which is also possibly responsible for the deactivation. By optimizing the catalyst preparation methods and reaction conditions, the 1-butene conversion of 92.1\% and propene selectivity of $79.1 \%$ have been achieved over $15 \mathrm{~W} / \mathrm{SBA}-15$ catalyst. Accordingly, the specific activity is about $7.4 \mathrm{mmol} \mathrm{C}_{4}^{\overline{ }}$ per $\mathrm{g}_{\text {cat }}$ per $\mathrm{h}$. The present study provides the molecular level structure-activity/selectivity relationship for the 1-butene/ethylene metathesis to propene. The comprehensive insights will guide us to develop advanced W-based catalysts for olefin metathesis to remarkably enhance the selectivity to desired olefins.

\section{Conflicts of interest}

There are no conflicts to declare.

\section{Acknowledgements}

The authors wish to acknowledge the financial support from the National Natural Science Foundation of China (21576119), the Natural Science Foundation of Jiangsu Province (BK20151125), the Fundamental Research Funds for the Central Universities (JUSRP51720B), the Jiangsu Provincial Six Talent Peaks Program (XNY-001), and the Programme of Introducing Talents of Discipline to Universities (111 Project B13025).

\section{References}

1 H. M. T. Galvis and K. P. de Jong, ACS Catal., 2013, 3, 21302149.

2 L. Yu, J. Yuan, Q. Zhang, Y. M. Liu, H. Y. He, K. N. Fan and Y. Cao, ChemSusChem, 2014, 7, 743-747.

3 Z. W. Xi, N. Zhou, Y. Sun and K. L. Li, Science, 2001, 292, 1139-1141.

4 A. Farshi, F. Shaiyegh, S. H. Burogerdi and A. Dehgan, Pet. Sci. Technol., 2011, 29, 875-885.

5 E. Epelde, M. Ibáñez, J. Valecillos, A. T. Aguayo, A. G. Gayubo, J. Bilbao and P. Castaño, Appl. Catal., A, 2017, 547, 176-182.

6 M. Sedighi, K. Keyvanloo and J. Towfighi, Fuel, 2013, 109, 432-438.

7 M. Bender, ChemBioEng Rev., 2014, 1, 136-147.

8 A. Corma, G. W. Huber, L. Sauvanaud and P. O'Connor, J. Catal., 2007, 247, 307-327.

9 Y. M. Liu, W. L. Feng, T. C. Li, H. Y. He, W. L. Dai, W. Huang, Y. Cao and K. N. Fan, J. Catal., 2006, 239, 125-136.

10 P. Tian, Y. X. Wei, M. Ye and Z. M. Liu, ACS Catal., 2015, 5, 1922-1938.

11 F. Jiang, M. Zhang, B. Liu, Y. B. Xu and X. H. Liu, Catal. Sci. Technol., 2017, 7, 1245-1265.
12 F. Jiang, B. Liu, W. P. Li, M. Zhang, Z. J. Li and X. H. Liu, Catal. Sci. Technol., 2017, 7, 4609-4621.

13 J. Zheng, J. Cai, F. Jiang, Y. B. Xu and X. H. Liu, Catal. Sci. Technol., 2017, 7, 4736-4755.

14 W. G. Zhou, J. Y. Liu, X. Wu, J. F. Chen and Y. Zhang, Catal. Commun., 2015, 60, 76-81.

15 R. Westhoff and J. A. Moulijn, J. Catal., 1977, 46, 414-416.

16 E. Mazoyer, K. C. Szeto, N. Merle, S. Norsic, O. Boyron, J. M. Basset, M. Taoufik and C. P. Nicholas, J. Catal., 2013, 301, 1-7.

17 S. J. Huang, S. L. Liu, W. J. Xin, J. Bai, S. J. Xie, Q. X. Wang and L. Y. Xu, J. Mol. Catal. A: Chem., 2005, 226, 61-68.

18 T. Hahn, E. V. Kondratenko and D. Linke, Chem. Commun., 2014, 50, 9060-9063.

19 X. J. Li, W. P. Zhang, S. L. Liu, S. J. Xie, X. X. Zhu, X. H. Bao and L. Y. Xu, J. Mol. Catal. A: Chem., 2009, 313, 38-43.

20 C. Meetings, Chemistry, 2003, 9, 971-975.

21 S. Lwin and I. E. Wachs, ACS Catal., 2015, 6, 272-278.

22 S. Lwin and I. E. Wachs, ACS Catal., 2014, 4, 2505-2520.

23 S. J. Huang, F. Chen, S. L. Liu, Q. Zhu, X. Zhu, W. J. Xin, Z. Feng, C. Li, Q. Wang and L. Y. Xu, J. Mol. Catal. A: Chem., 2007, 267, 224-233.

24 J. F. Wu, A. Ramanathan, W. K. Snavely, H. D. Zhu, A. Rokicki and B. Subramaniam, Appl. Catal., A, 2016, 528, 142-149.

25 V. Goelden, D. Linke and E. V. Kondratenko, ACS Catal., 2015, 5, 7437-7445.

26 S. Lwin, Y. Li, A. I. Frenkel and I. E. Wachs, ACS Catal., 2016, 6, 3061-3071.

27 S. Lwin and I. E. Wachs, ACS Catal., 2016, 7, 573-580.

28 D. R. Hua, S. L. Chen, G. M. Yuan, Y. L. Wang, Q. F. Zhao, X. L. Wang and B. Fu, Microporous Mesoporous Mater., 2011, 143, 320-325.

29 E. Mazoyer, K. C. Szeto, S. Norsic, A. Garron, J. M. Basset, C. P. Nicholas and M. Taoufik, ACS Catal., 2011, 1, 16431646.

30 Y. D. Wang, Q. L. Chen, W. M. Yang, Z. K. Xie, W. Xu and D. Y. Huang, Appl. Catal., A, 2003, 250, 25-37.

31 E. Mazoyer, K. C. Szeto, J. M. Basset, C. P. Nicholas and M. Taoufik, Chem. Commun., 2012, 48, 3611-3613.

32 J. L. Wang and H. R. Menapace, J. Catal., 1973, 28, 300-303. 33 W. Xu, C. Lin, H. Liu, H. B. Yu, K. Tao and S. H. Zhou, RSC Adv., 2015, 5, 23981-23989.

34 K. Tao, Q. X. Ma, N. Tsubaki, S. H. Zhou and L. Han, J. Mol. Catal. A: Chem., 2016, 416, 39-46.

35 W. L. Jiang, R. L. Huang, P. D. Li, S. Feng, G. L. Zhou, C. C. $\mathrm{Yu}, \mathrm{H}$. J. Zhou, C. M. Xu and Q. Xu, Appl. Catal., A, 2016, 517, 227-235.

36 N. Gholampour, M. Yusubov and F. Verpoort, Catal. Rev., 2016, 58, 113-156.

37 S. S. Geng, F. Jiang, Y. B. Xu and X. H. Liu, ChemCatChem, 2016, 8, 1303-1307.

38 J. Cai, F. Jiang and X. H. Liu, Appl. Catal., B, 2017, 210, 1-13. 39 T. Kim, A. Burrows, C. J. Kiely and I. Wachs, J. Catal., 2007, 246, 370-381.

40 V. M. Benitez and N. S. Fígoli, Catal. Commun., 2002, 3, 487492. 
41 E. Briot, J. Y. Piquemal, M. Vennat, J. M. Brégeault, G. Chottard and J. M. Manoli, J. Mater. Chem., 2000, 10, 953-958.

42 E. I. Ross-Medgaarden and I. E. Wachs, J. Phys. Chem. C, 2007, 111, 15089-15099.

43 C. Martín, G. Solana, V. Rives, G. Marci, L. Palmisano and A. Sclafani, Catal. Lett., 1997, 49, 235-243.

44 B. Hu, H. Liu, K. Tao, C. R. Xiong and S. H. Zhou, J. Phys. Chem. C, 2013, 117, 26385-26395.

45 C. Martín, G. Solana, P. Malet and V. Rives, Catal. Today, 2003, 78, 365-376.

46 L. Harmse, C. van Schalkwyk and E. van Steen, Catal. Lett., 2010, 137, 123-131.

47 N. Poovarawan, K. Suriye, J. Panpranot, W. Limsangkass, F. J. Cadete Santos Aires and P. Praserthdam, Catal. Lett., 2015, 145, 1868-1875.

48 S. Maksasithorn, P. Praserthdam, K. Suriye and D. P. Debecker, Microporous Mesoporous Mater., 2015, 213, 125-133.

49 D. Hunyadi, I. Sajó and I. M. Szilágyi, J. Therm. Anal. Calorim., 2013, 116, 329-337.

50 X. L. Yang, R. Gao, W. L. Dai and K. N. Fan, J. Phys. Chem. C, 2008, 112, 3819-3826.

51 C. Lin, K. Tao, H. B. Yu, D. Y. Hua and S. H. Zhou, Catal. Sci. Technol., 2014, 4, 4010-4019.

52 J. K. Jeon, H. Lee, J. H. Yim, Y. S. Kim, S. J. Lee, Y. K. Park, J. K. Shon and J. M. Kim, Catal. Lett., 2007, 119, 179-184.

53 X. L. Yang, W. L. Dai, R. H. Gao and K. N. Fan, J. Catal., 2007, 249, 278-288.

54 K. Amakawa, S. Wrabetz, J. Kröhnert, G. Tzolova-Müller, R. Schlögl and A. Trunschke, J. Am. Chem. Soc., 2012, 134, 11462-11473.
55 S. Doniach and M. Sunjic, J. Phys. Chem. C, 2001, 3, 285-291.

56 A. P. Shpak, A. M. Korduban, M. M. Medvedskij and V. O. Kandyba, J. Electron Spectrosc. Relat. Phenom., 2007, 156, 172-175.

57 J. C. Dupin, D. Gonbeau, P. Vinatier and A. Levasseur, Phys. Chem. Chem. Phys., 2000, 2, 1319-1324.

58 S. J. Huang, S. L. Liu, Q. J. Zhu, X. X. Zhu, W. J. Xin, H. J. Liu, Z. C. Feng, C. Li, S. J. Xie, Q. X. Wang and L. Y. Xu, Appl. Catal., A, 2007, 323, 94-103.

59 J. Howell, Y. P. Li and A. T. Bell, ACS Catal., 2016, 6, 77287738.

60 C. Martín, P. Malet, A. G. Solana and V. Rives, J. Phys. Chem. $B$, 1998, 102, 2759-2768.

61 H. Liu, K. Tao, H. B. Yu, C. Zhou, Z. Ma, D. S. Mao and S. H. Zhou, C. R. Chim., 2015, 18, 644-653.

62 K. Ding, A. Gulec, A. M. Johnson, T. L. Drake, W. Wu, Y. Lin, E. Weitz, L. D. Marks and P. C. Stair, ACS Catal., 2016, 6, 5740-5746.

63 P. Arudra, T. I. Bhuiyan, M. N. Akhtar, A. M. Aitani, S. S. AlKhattaf and H. Hattori, ACS Catal., 2014, 4, 4205-4214.

64 J. F. Wu, A. Ramanathan and B. Subramaniam, J. Catal., 2017, 350, 182-188.

65 A. G. Basrur, S. R. Patwardhan and S. N. Was, J. Catal., 1991, 127, 86-95.

66 G. Chen, M. Dong, J. F. Li, Z. W. Wu, G. F. Wang, Z. F. Qin, J. G. Wang and W. B. Fan, Catal. Sci. Technol., 2016, 6, 55155525.

67 Z. Cheng and C. S. Lo, ACS Catal., 2012, 2, 341-349.

68 Y. Chauvin, Angew. Chem., Int. Ed., 2006, 45, 3740-3747.

69 J. L. Hérisson and Y. Chauvin, Macromol. Chem. Phys., 1971, 141, 161-176. 